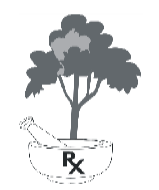

\title{
Quality attributes of twenty-nine brands of ciprofloxacin: post-marketing in vitro analyses, microbiological assay and in vivo simulation
}

\author{
Hashiya S. Muhammad ${ }^{1}$, Patience O. Okpe ${ }^{1}$, Patrick O. Olorunfemi ${ }^{1}$, Nelson A. Ochekpe ${ }^{1}$, \\ Wale R. Hamza ${ }^{2}$ and Ndidi C. Ngwuluka ${ }^{1^{*}}$ \\ ${ }^{1}$ Biomaterials and Drug Delivery Unit, Faculty of Pharmaceutical Sciences; ${ }^{2}$ Department of Physiology, \\ College of Health Sciences, University of Jos, 930001 Jos, Plateau State, Nigeria.
}

Received 12 $2^{\text {th }}$ June 2020; Accepted 24 ${ }^{\text {th }}$ August 2020

\begin{abstract}
Ciprofloxacin is a fluoroquinolone antibiotic employed to treat infections. There are over three hundred registered generic brands of ciprofloxacin in Nigeria. There has been an observed marked variation in therapeutic or clinical outcome with change in brands by health professionals and patients. In a previous study of six (6) brands we had reported a high degree of inequivalence. In this study, twenty-nine (29) brands of ciprofloxacin were extensively evaluated against compendia requirements. Microbial sensitivity against two test organisms was conducted. In-vitro drug release and in-vivo simulation were established. Analysis of the data generated indicated that all brands passed qualitative test using TLC and disintegration test, six failed hardness test, one failed friability, nine failed antimicrobial assay and six failed percentage content assay. Conclusions drawn from the study for evidence-based clinical decision would include the fact that three brands only were found to be bioequivalent to the innovator brand, Ciproxin; while eight brands were bio-inequivalent using the three models of similarity factor $\left(f_{2}\right)$, and difference factor $\left(f_{1}\right)$ in two media and dissolution efficiency (DE) in pH 4.5. The three brands (Cipro-All, Cifran And Ciprogem) may confidently be used interchangeably with the innovator brand
\end{abstract}

Keywords: Bioequivalence; Ciprofloxacin Drug quality; Generic substitution; Post-marketing surveillance

\section{INTRODUCTION}

Poor quality medicines such as substandard, counterfeit or falsified and degraded products are a global challenge. Poor quality medicines could lead to treatment failure, drug resistance, morbidity and mortality in extreme cases and eventual distrust in the health care system. In Nigeria, poor quality medicines are both locally produced and imported from countries such as China and India. While the regulatory body,
National Agency for Food and Drug Administration and Control (NAFDAC) try to mitigate against poor quality medicines, such medicines still flood the market mainly due to limited resources of the agency, porosity of the borders and corruption. Consequently, quality assurance of medicines from raw materials to administration, requires the involvement of all stakeholders from suppliers to end users. Poor quality medicines should be reported to the National Pharmacovigilance Centre (NPC) at

*Correspondence. E-mail: ndidi.ngwuluka@biodrudel.com Tel: +234-8100331517.

ISSN 0189-8442 
NAFDAC, with offices in some health facilities. Drug quality reporting involves all stakeholders especially the health care professionals who observe these medicines when procured and administered. Quality assessments of medicines are usually undertaken by regulatory bodies, designated laboratories, and those in academia. However, availability of data is necessary to ensure public enlightenment and control of procurement and administration of poorquality drugs. Collation of data by the Pharmacovigilance Centre will facilitate appropriate dissemination to health facilities.

A comprehensive assessment of a solid dose antimicrobial pharmaceutical product should include the evaluation of its attributes such as visual inspection of labelling and packaging, physicochemical properties of uniformity of weight, disintegration and dissolution rates; chemical assays of purity and content of Active Pharmaceutical Ingredient (API); and a compulsory microbiological evaluation. Where interchangeability of products is intended, a dissolution study (invitro and/or in-vivo) becomes necessary.

These product attributes have been the focus of several product evaluations after release into the market [1-4]. Chemical analysis and visual assessment have been used to identify poor-quality drugs prevalent in Asian and sub-Saharan African countries [5, 6]. Nayyar and co-workers [7] reviewed 21 surveys on antimalarial drugs from six classes and from 21 countries in sub-Saharan Africa. The review of the surveys indicated that $35 \%$ of the drugs failed chemical analysis, $36 \%$ failed packaging analysis and $20 \%$ were classified as falsified. WHO [8] states that a drug is said to be falsified when the product is found to be a deliberate or fraudulent misrepresentation of its identity, composition, source or record keeping for traceability, and pretend to have marketing authorization. Those involved in falsified products are in it for profit having a total disregard for public health and safety. The effects of poor-quality drugs include adverse drug events, treatment failure, prolonged illness, increased cost of treatment, antimicrobial resistance and increased morbidity and mortality. Nigeria has cases of deaths due to poor quality medicines. About four years ago (2016), an estimate of $41.96 \%$ of under-five malaria deaths was associated with administration of poor quality antimalarials [9]. Details on deaths caused by poorly compounded chloroquine, unintentional use of ethylene glycol in paracetamol syrup, fake meningitis vaccines, fake adrenaline, contaminated infusions, diethylene glycol in paracetamol and chlorpheniramine-based teething mixture (My Pikin) are in the public domain.

One underutilized approach to assist in the fight against poor quality of medicines is drug quality reporting. Pharmacovigilance reports regarding quality issues excluding issues relating to adverse drug reactions and medication errors are described as drug quality reporting. A drug quality reporting system (DQRS) receives reports submitted by health professionals and marketing authorization holders voluntarily on observed or suspected defects or quality issues related to marketed drug products [10]. Reporting poor quality drug products may protect the public from treatment failure, antimicrobial resistance, and adverse drug reactions. Such reports should lead to prompt inspections and laboratory analysis.

Ciprofloxacin is one of the most prescribed antibiotics. In Nigeria, it can be obtained without prescription and due to the demand, there are over 300 registered ciprofloxacin brands [11]. Registered medicines must be monitored to ensure they are not re-introduced into the market as substandard or falsified products over time. Antibiotics are one of the targeted classes of medicines for manufacture, importation and distribution of their substandard products and counterfeits due to their high volume of use. As a result, post- 
marketing surveillance is vital to sanitize the drug market and protect public health.

Although several studies on ciprofloxacin have been undertaken [1, 12-18], this study was prompted by several observations and reports from some hospitals in North-Eastern Nigeria of varying clinical/therapeutic responses of different brands of Ciprofloxacin $500 \mathrm{mg}$ tablets/caplets. Therapeutic failure often occurred with some brands of Ciprofloxacin $500 \mathrm{mg}$ tablets/caplets making physicians and patients insist on specific brands without a known scientific evidence. Consequently, the study was undertaken to assist the prescribers and pharmacists make evidenced-based choices regarding interchangeability of available generic ciprofloxacin products.

\section{EXPERIMENTAL}

Test Products. Twenty-nine (29) different brands of ciprofloxacin $500 \mathrm{mg}$ tablets/caplets available at the time of sampling were procured from Yola and Jos metropolis, capital cities of Adamawa and Plateau states, Nigeria. All test products procured for the study were registered with National Agency for Food Drug Administration and Control (NAFDAC) except the innovator brand, Ciproxin (Bayer, Pakistan, Batch No TRTOE8N) which was sourced abroad. The USP ciprofloxacin standard powder and standard tablets were gifts from a fellow scientist. Details of the twenty-nine (29) brands of ciprofloxacin tablets/caplets were as shown in Table 1. The methods were executed according to USP [19] with slight modifications as indicated in the methods.

\section{Physicochemical tests}

Visual inspection. This was undertaken in search of defects on labeling, packaging, and dosage forms. Required information on the package such as shelf-life, manufacturing date, dosage strength, dosage form and dosage description were assessed and documented.
Size, shape, and color were also observed and documented.

Uniformity tests. Laboratory tests such as weight variation and uniformity of thickness and diameter were executed as detailed in the USP [19].

Friability test. Resistance to abrasions and handling was determined as described in the USP [19] using a friabilator (Erweka, JM0004MG-001, Germany).

Hardness. To assess the tablet hardness, six tablets from each brand were employed using a hardness tester (Monsanto Tablet hardness tester, USA) to obtain the force required to break each tablet.

Disintegration. Six tablets from each brand in $900 \mathrm{~mL}$ of $0.1 \mathrm{HCl}$ at $37 \pm 0.5^{\circ} \mathrm{C}$ were also used for the disintegration test (Erweka ZT 720 disintegration tester, Germany). The time at which no particle remained on the mesh was recorded and the average time it took for the six tablets of each brand to disintegrate was determined.

Content assay. Ascertaining the quantity of ciprofloxacin in the tablets of the different brands was undertaken by crushing preweighed twenty tablets from each brand. Thereafter, an equivalent weight of $25 \mathrm{mg}$ of ciprofloxacin was dissolved in $25 \mathrm{~mL}$ of deionized water. This was further diluted to obtain a stock solution of $100 \mu \mathrm{g} / \mathrm{mL}$. Subsequently, $4 \mu \mathrm{g} / \mathrm{mL}$ was withdrawn from the stock and the absorbance was determined at $275 \mathrm{~nm}$. The percentage content in each brand was calculated after obtaining the equation of best line fit from calibrations carried out with the reference standard of ciprofloxacin.

In vitro drug release. The dissolution apparatus II (LOGANS dissolution system UDT-804, Thailand) was used at $50 \mathrm{rpm}$ in three different media $(0.1 \mathrm{~N} \mathrm{HCl}-\mathrm{pH} 1.2$; acetate buffer $\mathrm{pH} 4.5$ and phosphate buffer $\mathrm{pH}$ 6.8). The volume used for each medium was 
$900 \mathrm{~mL}$ equilibrated to $37 \pm 0.5^{\circ} \mathrm{C}$. Six tablets were tested from each brand in the different media. Samples $(5 \mathrm{~mL})$ were withdrawn at intervals of $5,10,15,20,25,30,45,60 \mathrm{~min}$ and same volumes were replaced with fresh medium to maintain sink conditions. The samples were filtered and assayed spectrophotometrically at $275 \mathrm{~nm}$.

Impurity profiling of ciprofloxacin brands. The procedure employed was according to the operation manual of Global Pharma Health Fund (GPHF) Minilab. Thin layer chromatography (TLC) was employed to determine the purity of the ciprofloxacin brands. The mobile phase was prepared comprising $10 \mathrm{~mL}$ methanol, $5 \mathrm{~mL}$ acetone, 2.5 $\mathrm{mL}$ toluene, $5 \mathrm{~mL}$ concentrated ammonia solution (25\%), pipetted into the TLC developing chamber. The chamber was tightly closed, and the content mixed thoroughly. The chamber wall was lined with filter paper and left for $5 \mathrm{~min}$; thus, ensuring saturation of the chamber with the solvent vapour. Standard stock solution of ciprofloxacin yielding 5 $\mathrm{mg} / \mathrm{mL}$ was prepared in water with ciprofloxacin $250 \mathrm{mg}$ standard tablet. Thereafter, $1 \mathrm{~mL}$ each was withdrawn from the stock solution to prepare $0.625 \mathrm{mg} / \mathrm{mL}$ and 0.5 $\mathrm{mg} / \mathrm{mL}$ and made up to $10 \mathrm{~mL}$ with methanol. Stock sample solutions were prepared with 500 $\mathrm{mg}$ tablets from each brand to yield $5 \mathrm{mg} / \mathrm{mL}$. From the stock solutions, $0.625 \mathrm{mg} / \mathrm{mL}$ was prepared for each brand. Thereafter, employing a micropipette, $2 \mu \mathrm{L}$ of working standard and sample solution were spotted at different points (origin line) on the TLC plate. The TLC plates were carefully loaded into the already saturated developing chamber containing the mobile phase. The jar was closed and the chromatoplate was left until the solvent front had moved to three quarter of the length of the plate. The developing time was 22 minutes. The plate was carefully removed, and the solvent front marked, excess solvent was left to evaporate and the chromatoplate was observed under UV light of $254 \mathrm{~nm}$ using a battery driven lamp and the Rf values deduced.

Microbiological assay of ciprofloxacin brands. Mueller Hinton broth was prepared according to manufacturer's directives and 5 $\mathrm{mL}$ of the broth was dispensed into bijou bottles and sterilized in an autoclave at $121^{\circ} \mathrm{C}$ for $15 \mathrm{~min}$. Similarly, Mueller Hinton agar was prepared according to manufacturer's directives and $20 \mathrm{~mL}$ each was dispensed into clean and dried bijou bottles, covered, and sterilized by autoclaving at $121^{\circ} \mathrm{C}$ for $15 \mathrm{~min}$. The test organisms, $S$. aureus and $P$. aeruginosa were inoculated into the broth, incubated overnight at $37^{\circ} \mathrm{C}$. The overnight culture was diluted to $0.5 \mathrm{McF}$ arland standard. The molten sterile agar was cooled to about 40$45^{\circ} \mathrm{C}$ and $0.1 \mathrm{~mL}$ of standardized inoculum was inoculated into the $20 \mathrm{~mL}$ of agar, mixed and poured into a Petri-dish and allowed to solidify. Thereafter, wells were punched into the agar with No 5 cork borer and the wells filled with $0.1 \mathrm{~mL}$ solutions of each of the brands and standard. Tests and standards were compared at three concentrations levels - 60, $30,15 \mu \mathrm{g} / \mathrm{mL}$. The plates were left on the bench for about one hour for pre-diffusion and were incubated for $24 \mathrm{~h}$ at $37^{\circ} \mathrm{C}$. The zones of inhibition were measured, the log potency ratio was calculated and the percentage content in each brand was determined.

Data analyses and in vivo simulation. Basic statistics such as standard deviation was employed to analyse the data obtained. DDSolver as an add-in to Microsoft excel was used to determine difference factor, $f_{l}$, similarity factor $f_{2}$ and dissolution efficiency. Microsoft excel and PKSolver were used for simulation of in vivo absorption and determination of pharmacokinetic parameters, respectively.

\section{RESULTS AND DISCUSSION}

Physicochemical evaluation. Tablets of all the brands were white except those of zibatab (yellow) and ciprotab (one side yellow and the 
other white). The tablets of the different brands were of three shape types - round, oval and oblong. Some of the brands had the brand names engraved on the tablets. Table 2 indicates the documented visual inspection of the brands of ciprofloxacin. There was no indication of any degraded tablets on visual inspection.

The outcomes of the physical parameters tested were as shown in Table 3. All brands passed weight variation test except siprosan, cipro-superior and zindocip with percentage deviations of 5.4, 6.6 and $20.1 \%$ respectively. These deviations were more than the USP specification for tablets weighing more than $342 \mathrm{mg}$ (not more than 5\%). Six brands, ciproheal, rumaxine, ciproall, zindocip, siprosan, and corflox failed hardness test with kilogram force below the required $4 \mathrm{kgF}$. Of concern may be the handling and transportation of these brands which may lead to fracture or chipping.

All brands passed the friability test except ciprogem with a percentage friability of $10.8 \pm 0.23$. The specification for friability is that tablets should be less than $1 \%$ friable. In our previous study, the batch of ciprogem purchased then passed friability test [1]. The manufacturer of ciprogem used to have the franchise and licence agreement to produce ciproxin until 2002. Consequently, one would expect consistency from them. Search for other publications on ciprofloxacin to monitor ciprogem's previous performances yielded limited results as some authors coded the brands [17, 20, 21] while those who did not code did not sample ciprogem $[12,15]$.

Table 1: Product information of the different brands of Ciprofloxacin

\begin{tabular}{|c|c|c|c|c|c|c|}
\hline $\mathrm{S} / \mathrm{N}$ & BRAND & BATCH NO & NAFDAC NO & MFD. DATE & *EXP. DATE & $\begin{array}{l}\text { COUNTRY } \\
\text { OF ORIGIN }\end{array}$ \\
\hline 1 & Prox & G014020 & $04-3565$ & 2014/APR & 2017/MAR & INDIA \\
\hline 2 & Rapidflox & E508 & $04-3221$ & 2015/MAR & 2019/MAR & INDIA \\
\hline 3 & Ciproheal & CF4030 & $04-7436$ & 2014/AUG & 2017/JUL & INDIA \\
\hline 4 & Rumaxine & O15 & A4-9152 & 2014/APR & 2017/MAR & PAKISTAN \\
\hline 5 & Cipro-all & $5 \mathrm{EO} 25$ & B4-1551 & 2015/MAY & 2018/APR & INDIA \\
\hline 6 & Ciprofax & 140615 & A4-0482 & 2014/JUN & 2017/JUN & CHINA \\
\hline 7 & Cipro-superior & 1506020 & A4-4889 & 2015/JUN & 2018/JUN & NIGERIA \\
\hline 8 & Cipad & 4T66004 & $04-6926$ & 2014/FEB & 2017/JAN & INDIA \\
\hline 9 & Cipro-Kriss & KP15173 & B4-0293 & 2015/AUG & 2016/JUL & NIGERIA \\
\hline 10 & Zindocip & 60429 & B4-2565 & 2014/JUN & 2019/JUN & CYRUS \\
\hline 11 & Vitapro & 5640626 & $04-2170$ & 2014/JUL & 2017/JUN & NIGERIA \\
\hline 12 & Pemcipro & 141221 & B4-3485 & 2014/DEC & 2017/DEC & CHINA \\
\hline 13 & Siprosan & SPS013A & $04-2107$ & 2014/AUG & 2017/JUL & NIGERIA \\
\hline 14 & Cenox & CNXH0160 & $04-3002$ & 2014/JAN & $2017 / \mathrm{NOV}$ & INDIA \\
\hline 15 & Zyprox & 129 & $04-9612$ & 2015/JUL & 2018/JUN & NIGERIA \\
\hline 16 & Cyplox & 640029 & $04-3202$ & 2014/JAN & 2016/DEC & INDIA \\
\hline 17 & Gecip & 141112 & $04-5856$ & 2014/NOV & 2017/NOV & CHINA \\
\hline 18 & Cipromaxfort & 14042001 & $04-4950$ & 2014/AUG & 2017/AUG & CHINA \\
\hline 19 & Ciflaxin & $100 \mathrm{EO} 1$ & 04-9097 & 2014/MAY & 2018/APR & NIGERIA \\
\hline 20 & VPL & 140727 & B4-0053 & 2014/JUL & 2017/JUL & CHINA \\
\hline 21 & Ciprof & GT15010 & $04-4772$ & 2015/FEB & 2019/JAN & INDIA \\
\hline 22 & Zibatab & ZXU011402 & B4-2220 & 2014/JUN & 2017/MAY & INDIA \\
\hline 23 & Corflox & 4385 & B4-3322 & 2014/DEC & $2017 / \mathrm{NOV}$ & INDIA \\
\hline 24 & Cifran & 2662288 & $04-4673$ & 2014/DEC & $2017 / \mathrm{NOV}$ & INDIA \\
\hline 25 & Grakkoflox & GK14001 & B4-0121 & 2014/FEB & 2017/JAN & INDIA \\
\hline 26 & Cipronol & 150102 & $04-6340$ & 2015/FEB & 2017/DEC & CHINA \\
\hline 27 & Ciproxin & TRTOE8N & NIL & NIL & 2019/JUN & PAKISTAN \\
\hline 28 & Ciprogem & $3641 \mathrm{H}$ & $04-4699$ & 2015/MAR & 2020/FEB & NIGERIA \\
\hline 29 & Ciprotab & VG1329 & $04-0723$ & 2014/JAN & 2016/DEC & INDIA \\
\hline
\end{tabular}

*The study was undertaken from late 2015 to 2016 before the expiry dates of the products. All brands were within their shelf lives at the time of the study. 
H.S. Muhammad et al. / J. Pharmacy \& Bioresources 17(2), 208-233 (2020)

Table 2: Visual assessment of the different brands of ciprofloxacin

\begin{tabular}{|c|c|c|c|c|c|}
\hline $\mathrm{S} / \mathrm{N}$ & BRAND & Pack size & PACKAGE & DOSAGE FORM & DESCRIPTION \\
\hline 1 & Prox & $2 \times 7$ & Alu/Alu blister* & Film coated caplet & White/ Oblong/ Scored on one side \\
\hline 2 & Rapidflox & $2 \times 7$ & Alu/Alu blister & Film coated caplet & $\begin{array}{l}\text { White/ Oblong/ Scored on one side and } \\
\text { "Rapidflox" engraved on the other side }\end{array}$ \\
\hline 3 & Ciproheal & $1 \times 10$ & Alu/Pvc blister** & Film coated caplet & $\begin{array}{l}\text { White/ Oval/ "Maxheal" engraved on one side } \\
\text { and "Ciprof 500" on the other side }\end{array}$ \\
\hline 4 & Rumaxine & $2 \times 7$ & Alu/Alu blister & Film coated tablet & White/ Round \\
\hline 5 & Cipro-all & $1 \times 10$ & Alu/Alu blister & Film coated caplet & White/ Oblong/ Scored on one side \\
\hline 6 & Ciprofax & $1 \times 10$ & Alu/Alu blister & Film coated caplet & $\begin{array}{l}\text { White/ Oblong/ Scored on one side and } \\
\text { "Ciprofax 500" engraved on the other side }\end{array}$ \\
\hline 7 & Cipro-sup & $1 \times 10$ & Alu/Alu blister & Film coated caplet & White/ Oblong/ Scored on one side \\
\hline 8 & Cipad & $1 \times 10$ & Alu/Pvc blister & Film coated caplet & $\begin{array}{l}\text { White/ Oblong/ Scored on one side and "AD" } \\
\text { engraved on the other side }\end{array}$ \\
\hline 9 & Cipro-Kriss & $1 \times 10$ & Alu/Pvc blister & Film coated caplet & White /Oval/ "Cipro 500" engraved on one side \\
\hline 10 & Zindocip & $1 \times 10$ & Alu/Pvc blister & Film coated caplet & $\begin{array}{l}\text { White/ Oblong/ Scored on one side with "Zin" } \\
\text { and " } 2 \text { ' engraved on that side and "500" on the } \\
\text { other side }\end{array}$ \\
\hline 11 & Vitapro & $1 \times 10$ & Alu/Pvc blister & Film coated caplet & White/ Oblong/ "Vitapro" engraved on one side \\
\hline 12 & Pemcipro & $1 \times 10$ & Alu/Alu blister & Film coated caplet & $\begin{array}{l}\text { White/ Oblong/ Scored on one side and } \\
\text { "Pemcipro 500" engraved on the other side }\end{array}$ \\
\hline 13 & Siprosan & $2 \times 7$ & Alu/Pvc blister & Film coated caplet & $\begin{array}{l}\text { White/ Oblong/ Scored on one side and } \\
\text { "Tyonex" engraved on the other side }\end{array}$ \\
\hline 14 & Cenox & $1 \times 10$ & Alu/Alu blister & Film coated caplet & $\begin{array}{l}\text { White/ Oblong/ White/ Oblong/ "Cenox" } \\
\text { engraved on one side }\end{array}$ \\
\hline 15 & Zyprox & $2 \times 7$ & Alu/Alu blister & Film coated caplet & $\begin{array}{l}\text { White/ Oblong/ "500" engraved on one side and } \\
\text { "Zyprox" on the other side }\end{array}$ \\
\hline 16 & Cyplox & $1 \times 10$ & Alu/Alu blister & Film coated caplet & $\begin{array}{l}\text { White/ Oblong/ "Cyplox 500" engraved on one } \\
\text { side }\end{array}$ \\
\hline 17 & Gecip & $1 \times 10$ & Alu/Alu blister & Film coated caplet & $\begin{array}{l}\text { White/ Oblong/ Scored and "CP-500" engraved } \\
\text { on that side }\end{array}$ \\
\hline 18 & Cipromaxfort & $1 \times 10$ & Alu/Pvc blister & Film coated caplet & White/ Oval/ "Cipro 500" engraved on one side \\
\hline 19 & Ciflaxin & $1 \times 10$ & Alu/Pvc blister & Film coated caplet & $\begin{array}{l}\text { White/ Oblong/ "Drugfield" engraved on one } \\
\text { side }\end{array}$ \\
\hline 20 & VPL-Cipro & $1 \times 10$ & Alu/Alu blister & Film coated caplet & $\begin{array}{l}\text { White/ Oblong/ Scored on one side and "VPL- } \\
\text { C" engraved on the other side }\end{array}$ \\
\hline 21 & Ciprof & $1 \times 10$ & Alu/Alu blister & Film coated caplet & $\begin{array}{l}\text { White /Oblong/ "Ciprof 500" engraved on one } \\
\text { side }\end{array}$ \\
\hline 22 & Zibatab & $2 \times 7$ & Alu/Alu blister & Film coated caplet & Yellow/ Oblong/ Scored on one side \\
\hline 23 & Corflox & $2 \times 7$ & Alu/Alu blister & Film coated caplet & White/ Oblong/ Plain \\
\hline 24 & Cifran & $1 \times 10$ & Alu/Pvc blister & Film coated tablet & $\begin{array}{l}\text { White/ Round/ "CFT" engraved on one side and } \\
500 \text { engraved on the other side }\end{array}$ \\
\hline 25 & Grakkoflox & $1 \times 10$ & Alu/Alu blister & Film coated caplet & White/ Oblong/ Scored on one side \\
\hline 26 & Cipronol & $1 \times 10$ & Alu/Pvc blister & Film coated caplet & White /Oval/ "Cipro 500" engraved on one side \\
\hline 27 & Ciproxin & $1 \times 10$ & Alu/Pvc blister & Film coated caplet & $\begin{array}{l}\text { White/ Oblong/ Scored on one side with "Cip - } \\
500 " \text { engraved on that side and "BAYER" on the } \\
\text { other side }\end{array}$ \\
\hline 28 & Ciprogem & $1 \times 10$ & Alu/Pvc blister & Film coated caplet & $\begin{array}{l}\text { White/ Oblong/ Scored on one side with "CIP- } \\
500 " \text { on that side and "Gemini" engraved on the } \\
\text { other side }\end{array}$ \\
\hline 29 & Ciprotab & $1 \times 14$ & Alu/Pvc blister & Film coated caplet & $\begin{array}{l}\text { Yellow on one side and "Ciprotab" written on } \\
\text { one side and milky colour on the other side }\end{array}$ \\
\hline
\end{tabular}

* Tablets packed with aluminium blister all through. **Tablets packed with aluminium blister on one side and polyvinyl chloride (pvc) plastic on the other side. 
Table 3: Physical attributes of ciprofloxacin brands

\begin{tabular}{|c|c|c|c|c|c|c|c|c|}
\hline $\mathrm{S} / \mathrm{N}$ & Brands & $\begin{array}{c}\text { Weight } \\
(\mathrm{mg}) \pm \mathrm{SD}\end{array}$ & $\begin{array}{c}\% \\
\text { Dev. }\end{array}$ & $\begin{array}{l}\text { Hardness } \\
(\mathrm{KgF}) \pm \mathrm{SD}\end{array}$ & $\begin{array}{c}\text { Friability } \\
(\%)\end{array}$ & $\begin{array}{l}\text { Disintegration } \\
(\min ) \pm \mathrm{SD}\end{array}$ & $\begin{array}{l}\text { Thickness } \\
(\mathrm{mm}) \pm \mathrm{SD}\end{array}$ & $\begin{array}{l}\text { Diameter } \\
(\mathrm{mm}) \pm \mathrm{SD}\end{array}$ \\
\hline 1 & Prox & $661 \pm 0.007$ & 1.1 & $8.2 \pm 1.1$ & 0.015 & $9.0 \pm 0.6$ & $5.7 \pm 0.07$ & $6.6 \pm 0.01$ \\
\hline 2 & Rapidflox & $631 \pm 0.008$ & 1.3 & $4.5 \pm 1.0$ & 0.159 & $4.0 \pm 0.2$ & $5.4 \pm 0.08$ & $7.7 \pm 0.03$ \\
\hline 3 & Ciproheal & $754 \pm 0.009$ & 1.2 & $3.4 \pm 0.4$ & 0.108 & $6.6 \pm 0.7$ & $5.8 \pm 0.06$ & $9.1 \pm 0.02$ \\
\hline 4 & Rumaxine & $679 \pm 0.018$ & 2.6 & $3.5 \pm 0.3$ & 0.319 & $4.7 \pm 0.5$ & $5.6 \pm 0.05$ & $13 \pm 0.1$ \\
\hline 5 & Ciproall & $659 \pm 0.014$ & 2.1 & $3.8 \pm 0.3$ & 0.227 & $2.9 \pm 0.3$ & $5.1 \pm 0.02$ & $8.2 \pm 0.04$ \\
\hline 6 & Ciprofax & $898 \pm 0.015$ & 1.7 & $4.0 \pm 0.4$ & 0.232 & $3.5 \pm 0.6$ & $5.4 \pm 0.05$ & $9.1 \pm 0.01$ \\
\hline 7 & Cipro-Superior & $864 \pm 0.057$ & 6.6 & $4.5 \pm 0.2$ & 0.106 & $7.5 \pm 2.0$ & $5.3 \pm 0.04$ & $9.2 \pm 0.01$ \\
\hline 8 & Cipad & $721 \pm 0.009$ & 1.3 & $4.7 \pm 0.3$ & 0.125 & $2.9 \pm 0.3$ & $5.6 \pm 0.04$ & $8.2 \pm 0.02$ \\
\hline 9 & Cipro-Kriss & $771 \pm 0.162$ & 20.1 & $4.5 \pm 0.3$ & 0.063 & $3.8 \pm 0.3$ & $5.3 \pm 0.12$ & $9.3 \pm 0.02$ \\
\hline 10 & Zindocip & $801 \pm 0.012$ & 1.5 & $3.4 \pm 0.5$ & 0.137 & $4.4 \pm 0.2$ & $6.4 \pm 0.05$ & $8.1 \pm 0.02$ \\
\hline 11 & Vitapro & $919 \pm 0.015$ & 1.7 & $4.0 \pm 0.3$ & 0.032 & $1.1 \pm 0.3$ & $5.3 \pm 0.09$ & $9.4 \pm 0.02$ \\
\hline 12 & Pemcipro & $885 \pm 0.027$ & 3.1 & $4.9 \pm 0.7$ & 0.033 & $11.6 \pm 0.9$ & $5.3 \pm 0.05$ & $9.2 \pm 0.02$ \\
\hline 13 & Siprosan & $614 \pm 0.033$ & 5.4 & $3.7 \pm 0.3$ & 0.016 & $3.2 \pm 0.2$ & $4.9 \pm 0.14$ & $7.6 \pm 0.01$ \\
\hline 14 & Cenox & $798 \pm 0.006$ & 0.7 & $4.7 \pm 0.8$ & 0.012 & $3.1 \pm 0.4$ & $6.3 \pm 0.02$ & $8.2 \pm 0.03$ \\
\hline 15 & Zyprox & $674 \pm 0.016$ & 2.3 & $5.0 \pm 1.0$ & 0.084 & $4.8 \pm 1.2$ & $5.5 \pm 0.19$ & $9.1 \pm 0.07$ \\
\hline 16 & Cyplox & $1034 \pm 0.02$ & 1.9 & $6.8 \pm 1.5$ & 0.087 & $2.0 \pm 0.3$ & $6.9 \pm 0.02$ & $9.8 \pm 0.03$ \\
\hline 17 & Gecip & $716 \pm 0.011$ & 1.5 & $8.9 \pm 1.9$ & 0.015 & $22.2 \pm 1.7$ & $5.9 \pm 0.15$ & $8.2 \pm 0.01$ \\
\hline 18 & Cipromaxfort & $802 \pm 0.008$ & 1 & $11.1 \pm 0.3$ & 0.113 & $4.0 \pm 0.3$ & $5.5 \pm 0.02$ & $9.2 \pm 0.01$ \\
\hline 19 & Ciflaxin & $734 \pm 0.015$ & 2.1 & $9.0 \pm 0.9$ & 0.082 & $10.3 \pm 0.4$ & $6.3 \pm 0.08$ & $7.3 \pm 0.04$ \\
\hline 20 & Vpl-Cipro & $733 \pm 0.004$ & 0.6 & $10.4 \pm 0.9$ & 0.068 & $3.7 \pm 0.4$ & $4.9 \pm 0.12$ & $9.1 \pm 0.02$ \\
\hline 21 & Ciprof-500 & $787 \pm 0.012$ & 1.6 & $6.9 \pm 1.4$ & 0.405 & $1.6 \pm 0.4$ & $4.9 \pm 0.07$ & $9.2 \pm 0.09$ \\
\hline 22 & Zibatab & $775 \pm 0.008$ & 1.1 & $8.0 \pm 1.9$ & 0.065 & $6.4 \pm 0.1$ & $5.9 \pm 0.05$ & $8.6 \pm 0.01$ \\
\hline 23 & Corflox & $707 \pm 0.009$ & 1.3 & $3.6 \pm 0.4$ & 0.154 & $2.1 \pm 0.7$ & $4.8 \pm 0.09$ & $8.3 \pm 0.03$ \\
\hline 24 & Cifran & $767 \pm 0.007$ & 0.9 & $7.4 \pm 0.8$ & 0 & $1.3 \pm 0.2$ & $4.5 \pm 0.05$ & $13.2 \pm 0.01$ \\
\hline 25 & Grakkoflox & $626 \pm 0.011$ & 1.8 & $6.4 \pm 1.0$ & 0.063 & $10.5 \pm 0.4$ & $5.1 \pm 0.03$ & $8.4 \pm 0.01$ \\
\hline 26 & Cipronol & $741 \pm 0.007$ & 0.9 & $9.8 \pm 0.2$ & 0.027 & $2.5 \pm 0.5$ & $5.4 \pm 0.02$ & $9.1 \pm 0.02$ \\
\hline 27 & Ciproxin & $759 \pm 0.006$ & 0.8 & $12.2 \pm 1.0$ & 0.039 & $2.5 \pm 0.3$ & $5.6 \pm 0.07$ & $8.4 \pm 0.03$ \\
\hline 28 & Ciprogem & $778 \pm 0.006$ & 0.8 & $5.1 \pm 1.1$ & 10.8 & $1.4 \pm 0.7$ & $5.5 \pm 0.13$ & $8.2 \pm 0.02$ \\
\hline 29 & Ciprotab & $794 \pm 0.012$ & 1.5 & SOFTLET & 0.025 & $17.5 \pm 1.5$ & $5.9 \pm 0.04$ & $7.8 \pm 0.05$ \\
\hline
\end{tabular}

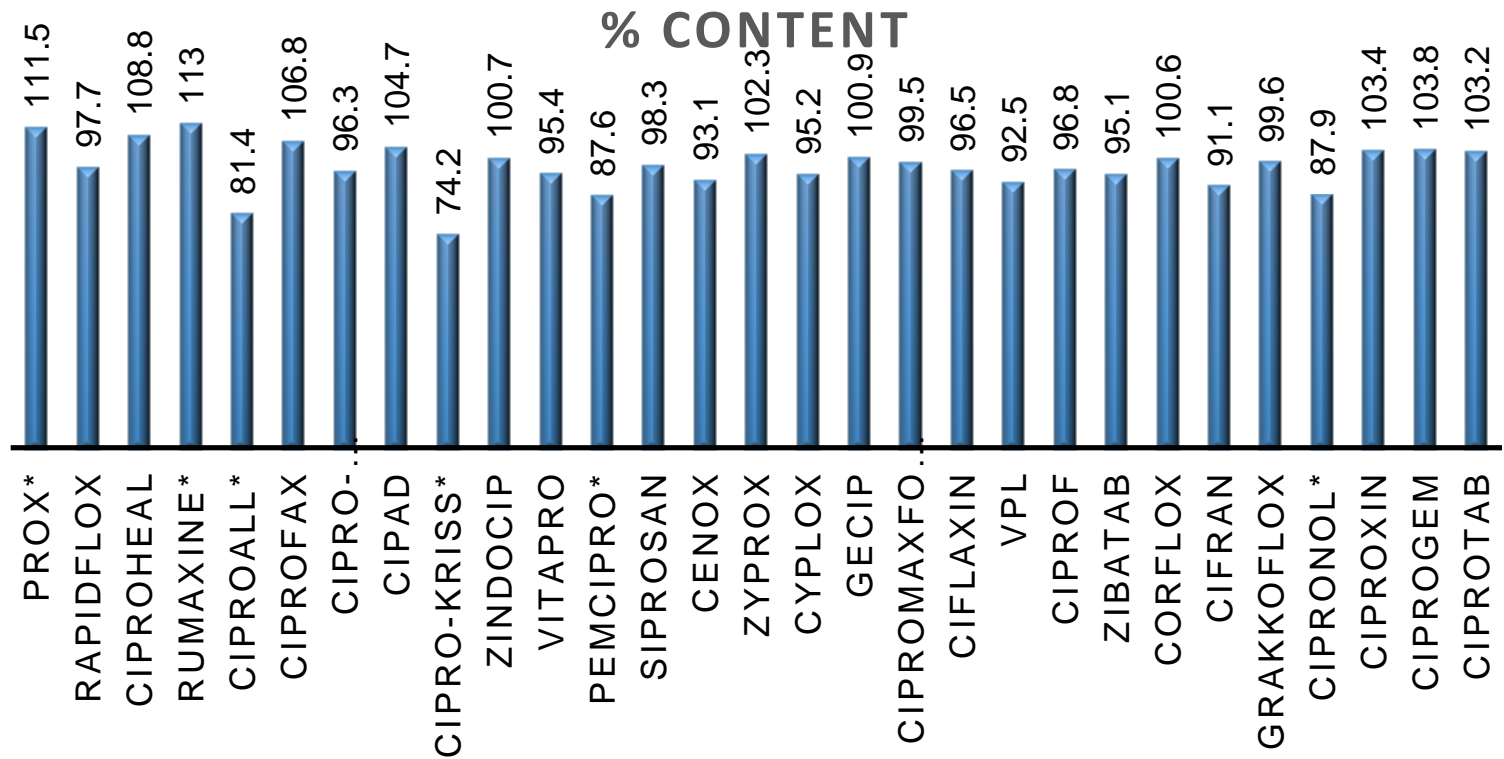

Fig. 1. Percentage content of ciprofloxacin in the various brands of ciprofloxacin hydrochloride. 


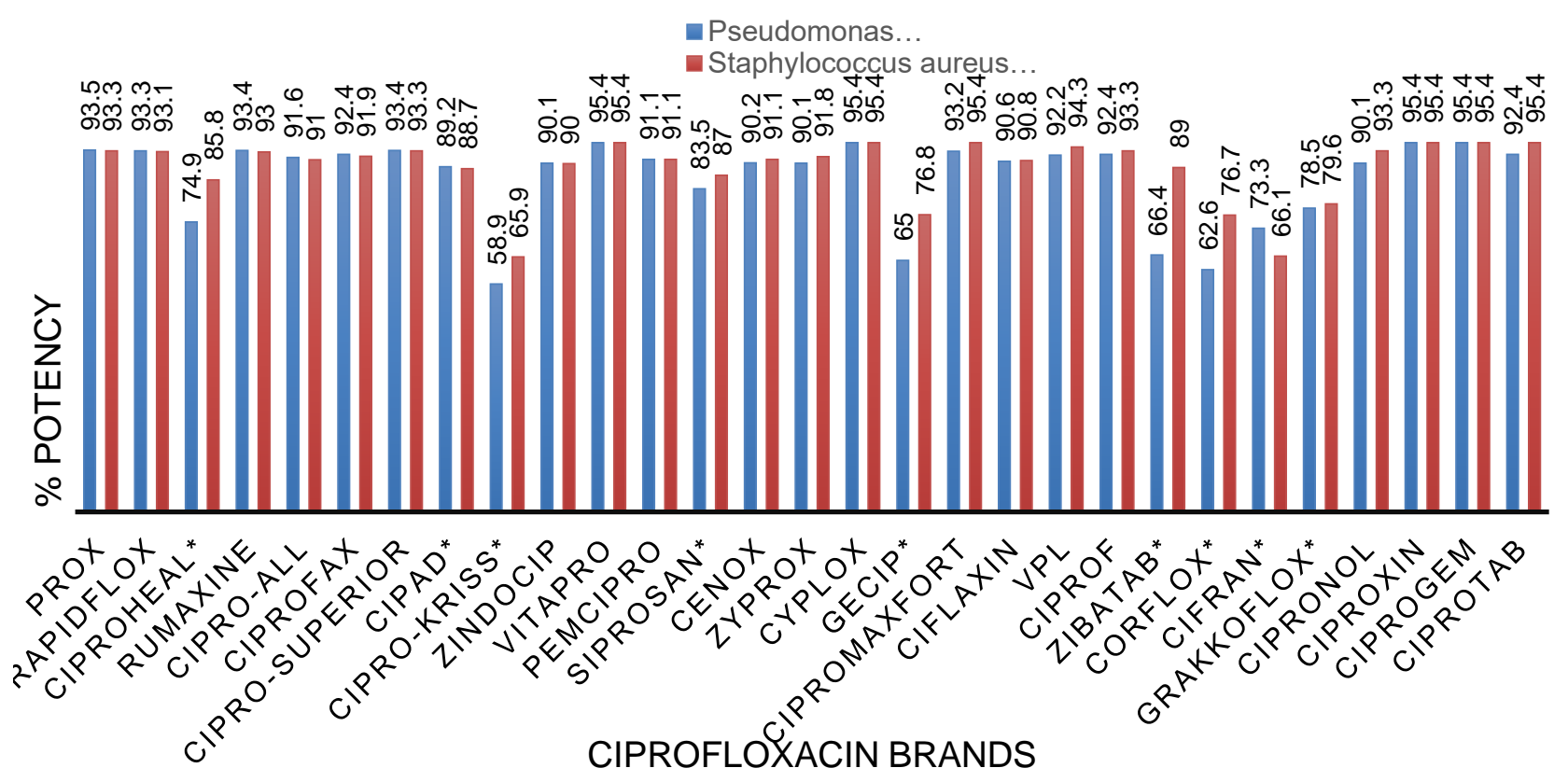

Fig. 2. Percentage potencies of the various brands of ciprofloxacin hydrochloride
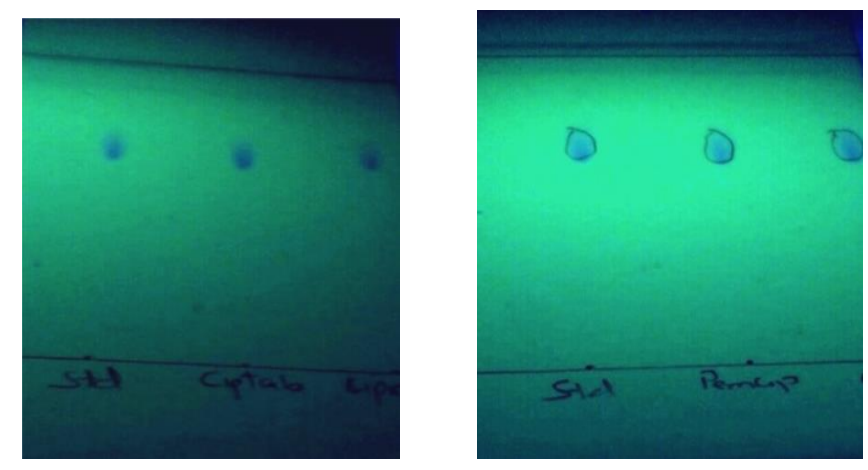

Fig. 3. Sample plates of the impurity testing using TLC

While coding the brands may protect the manufacturers, it does not provide the prescribers, pharmacists, and patients the opportunity to make informed decision on generic substitution. If the failure of the friability test of ciprogem is batch related, then it can be taken as an indication of failure of internal quality control mechanism.

In a previous study, all the brands of ciprofloxacin sampled passed the hardness and only one brand failed friability test [21] while a reverse was observed in another study where all brands passed friability test and two failed hardness test [17]. The degree of hardness of a tablet influences friability, disintegration, and drug release. It is expected that the harder the tablet, the less friable, the slower the disintegration and rate of drug release. It should not be surprising to see harder tablets disintegrate faster since the intrinsic property of a disintegrant influences rate of disintegration. All brands in this study, passed disintegration time test as the times for disintegration were within $30 \mathrm{~min}$. Vitapro had the least disintegration time of $1.1 \pm 0.3 \mathrm{~min}$ while Gecip had the longest disintegration time of $22.2 \pm 1.7 \mathrm{~min}$. All brands passed the thickness and diameter tests $(12.5 \mathrm{~mm}$ to be $\pm 5 \%$ and tablets with diameter up to $15 \mathrm{~mm}$ to be $\pm 3 \%$ ). 


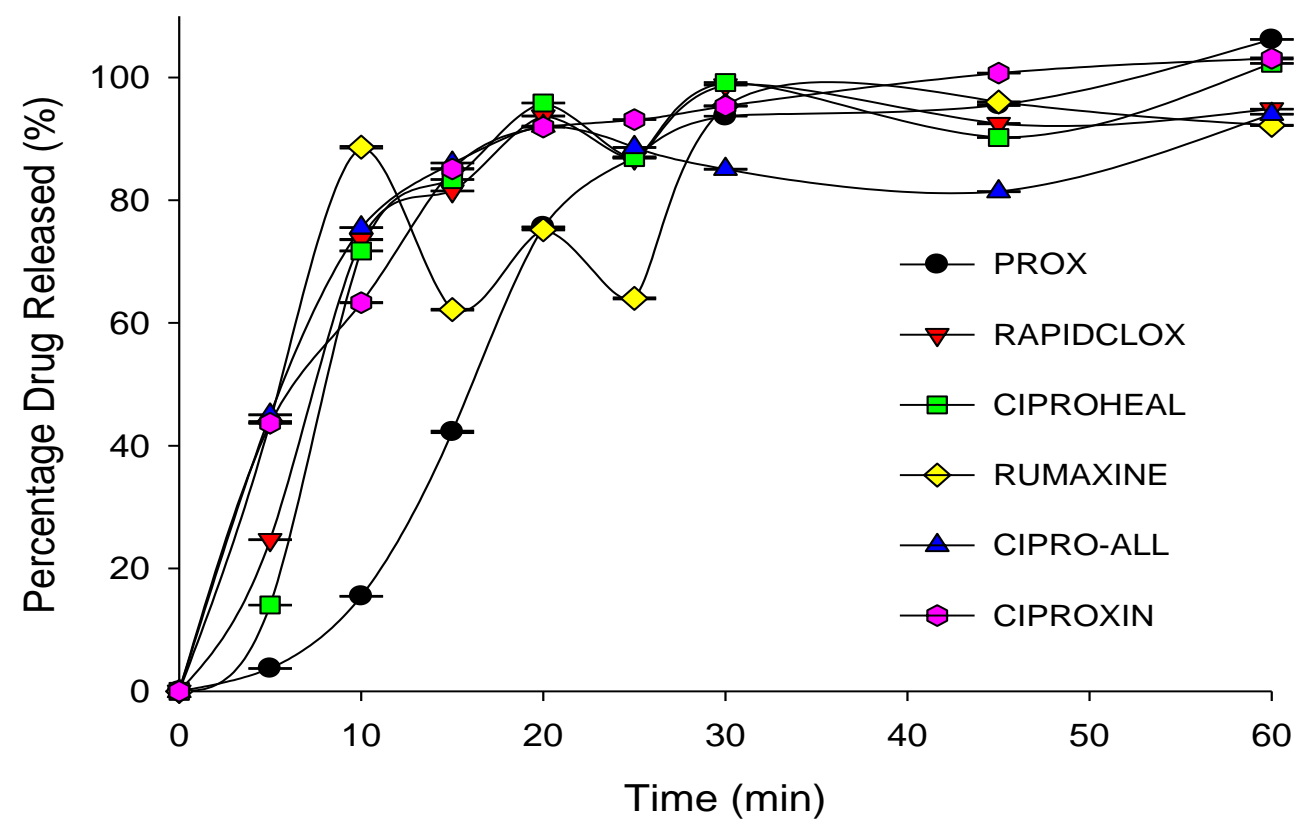

Fig. 4. Percentage Drug Release Profiles of Brands Prox, Rapidflox, Ciproheal, Rumaxine and Cipro-all in 0.1N $\mathrm{HCl}$ in comparision with ciproxin

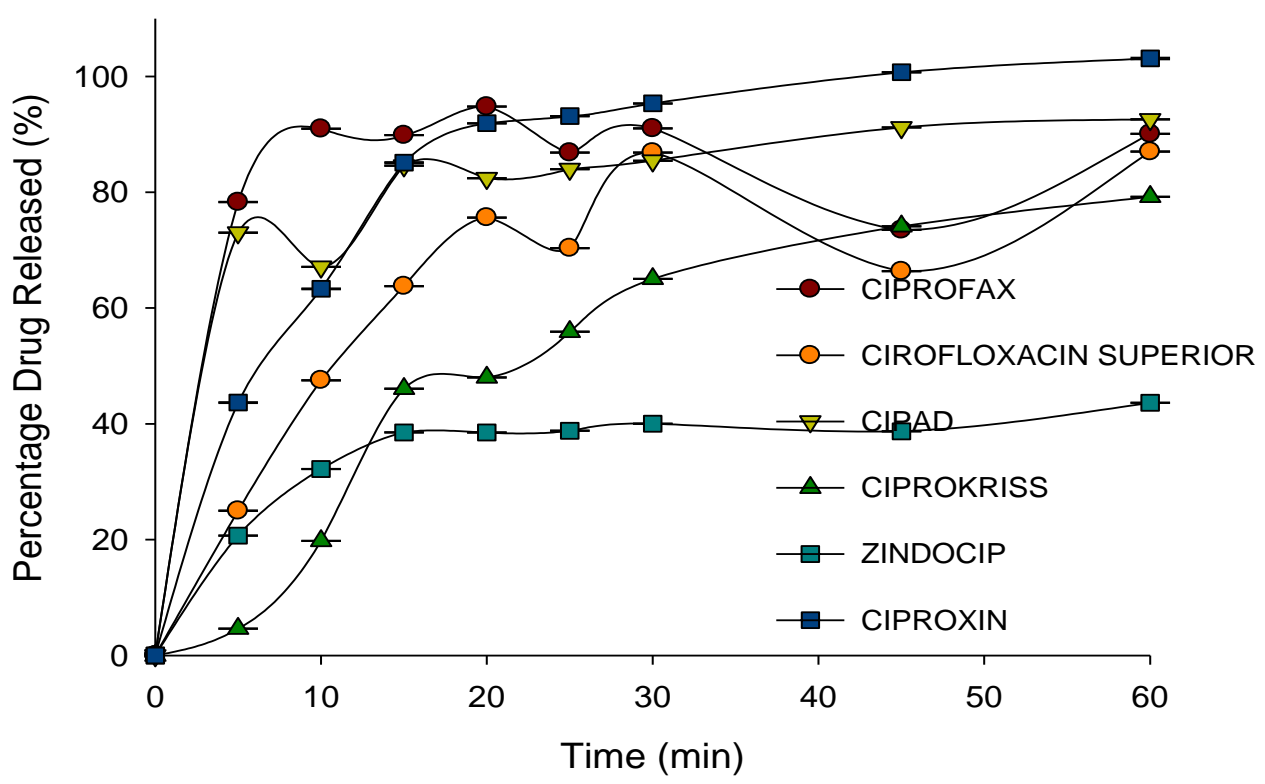

Fig. 5. Percentage Drug Release Profiles of Brands Ciprofax, Ciprofloxacin superior, Cipad, Ciprokriss and Zindocip in $0.1 \mathrm{~N} \mathrm{HCl}$ in comparision with ciproxin 


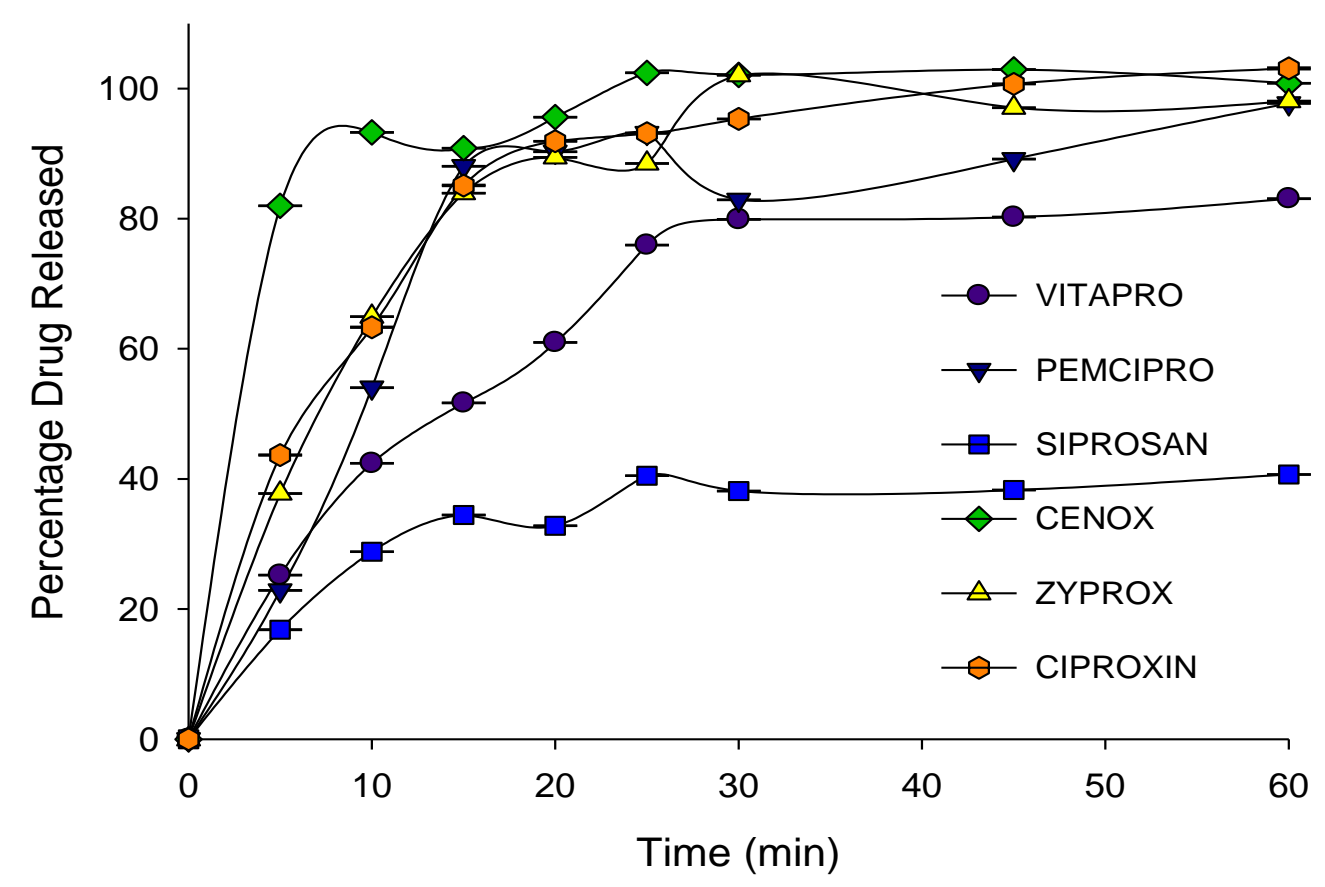

Fig. 6. Percentage Drug Release Profiles of Brands Vitapro, Pemcipro, Siprosan, Cenox and Zyprox in $0.1 \mathrm{~N} \mathrm{HCl}$ in comparision with ciproxin

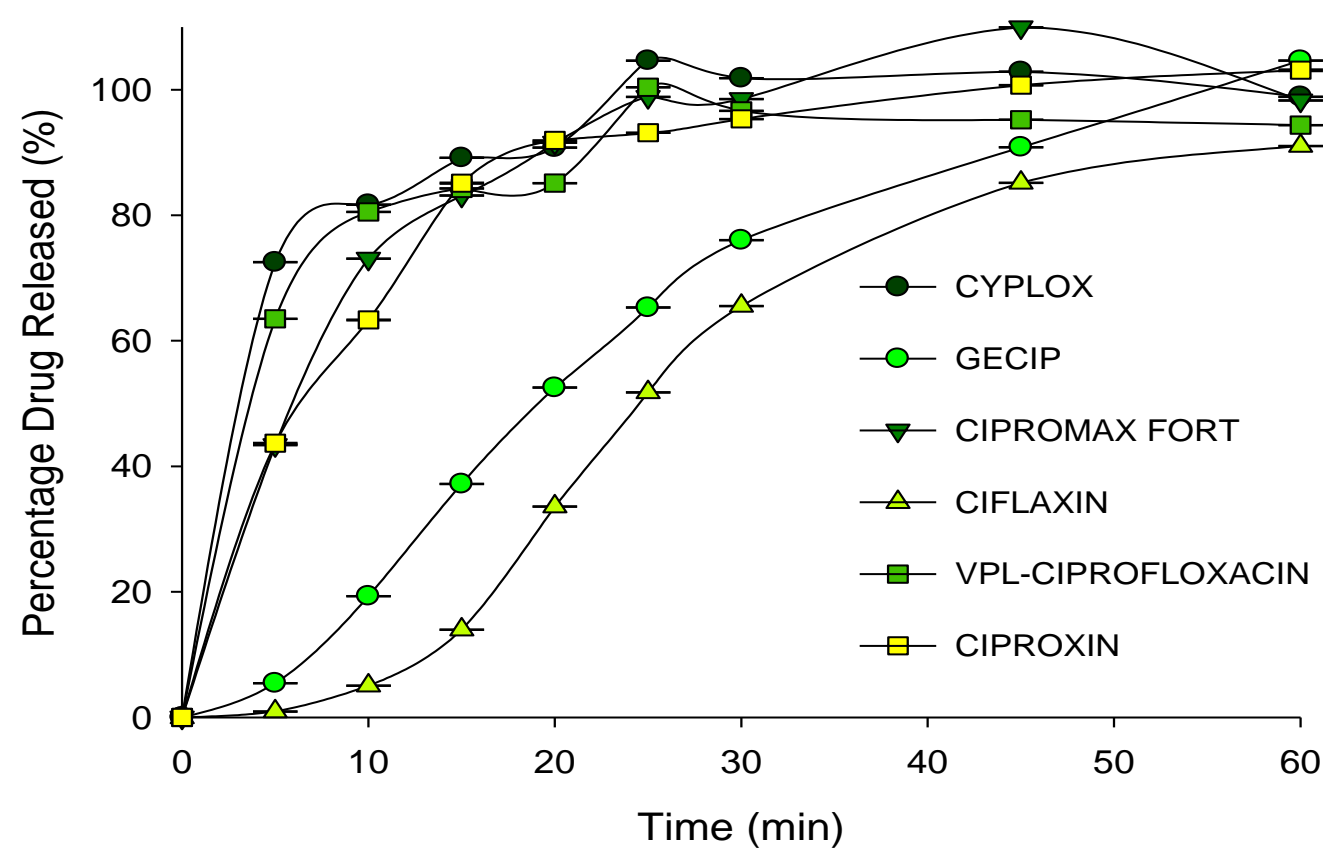

Fig. 7. Percentage Drug Release Profiles of Brands Cyplox, Gecip, Cipromax fort, Ciflaxin and VPL-Ciprofloxacin in $0.1 \mathrm{~N} \mathrm{HCl}$ in comparision with ciproxin 


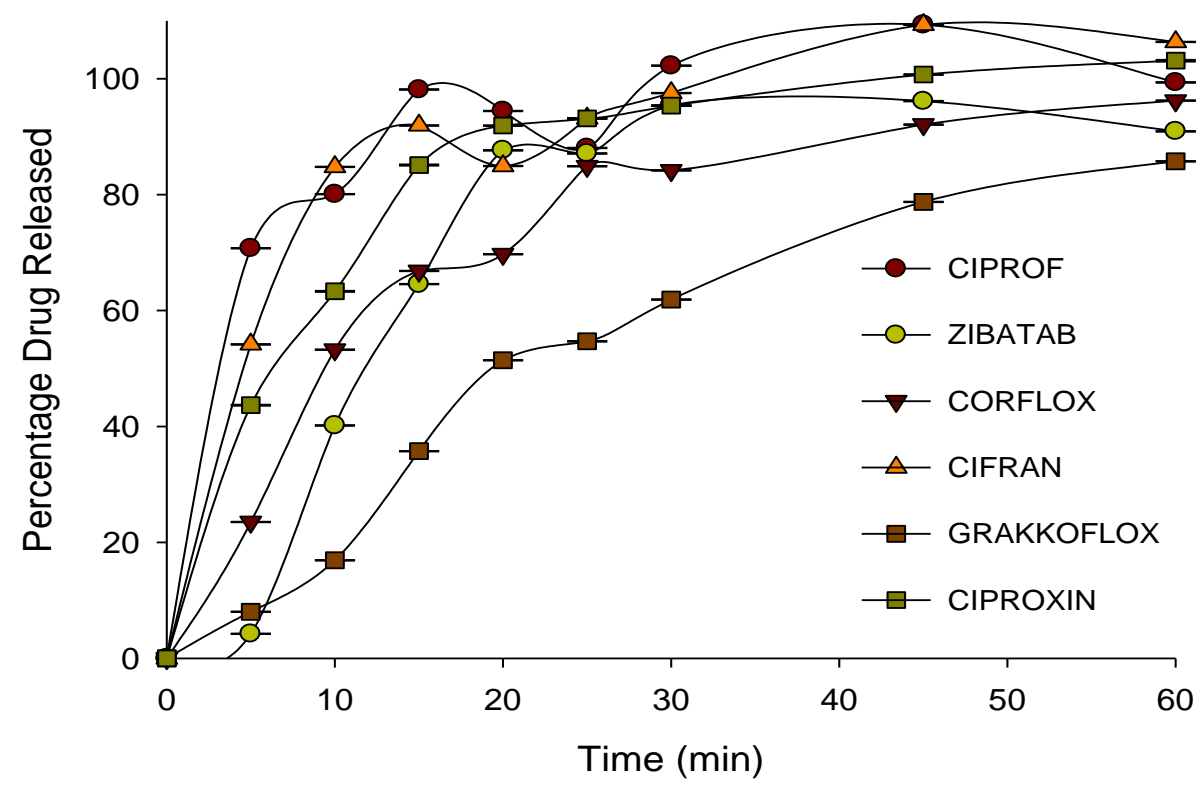

Fig. 8. Percentage Drug Release Profiles of Brands Ciprof, Zibatab, Corflox, Cifran and Grakkoflox in $0.1 \mathrm{~N} \mathrm{HCl}$ in comparision with ciproxin

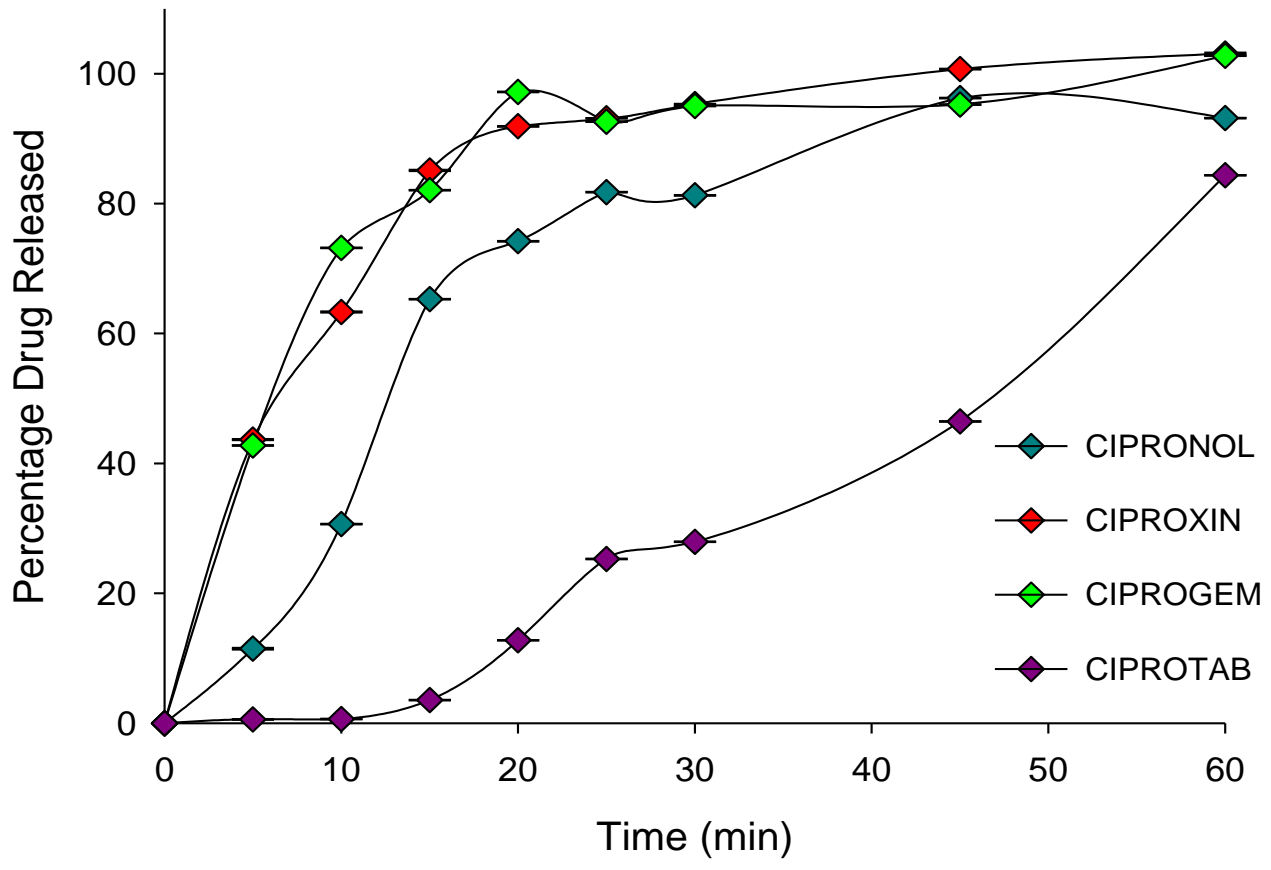

Fig. 9. Percentage Drug Release Profiles of Brands Cipronol, Ciproxin, Ciprogem and Ciprotab in $0.1 \mathrm{~N} \mathrm{HCl}$ in comparision with ciproxin 


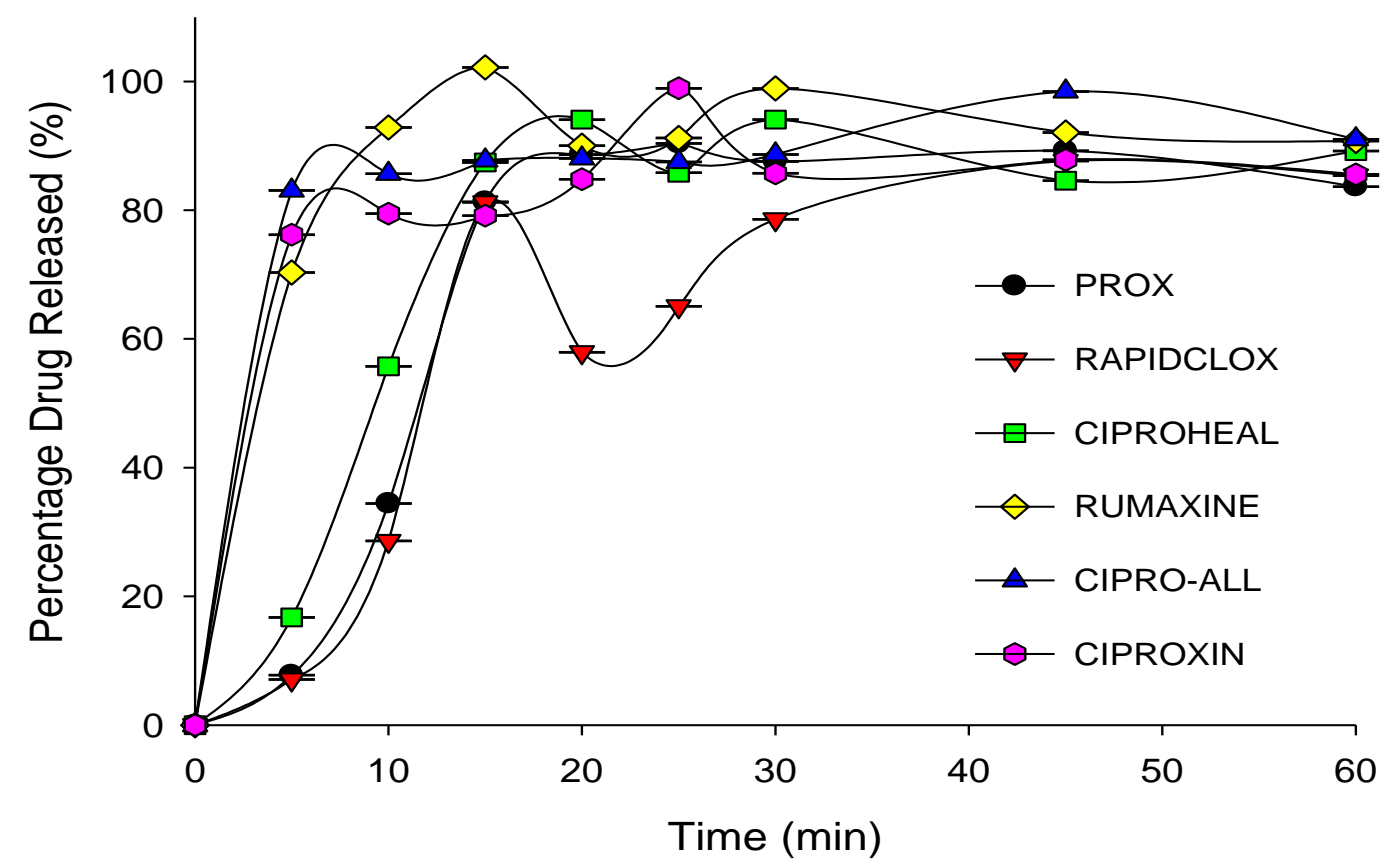

Fig. 10. Percentage Drug Release Profiles with Time of Brands Prox, Rapidflox, Ciproheal, Rumaxine and Cipro-all in Acetate Buffer pH 4.5 in comparision with ciproxin

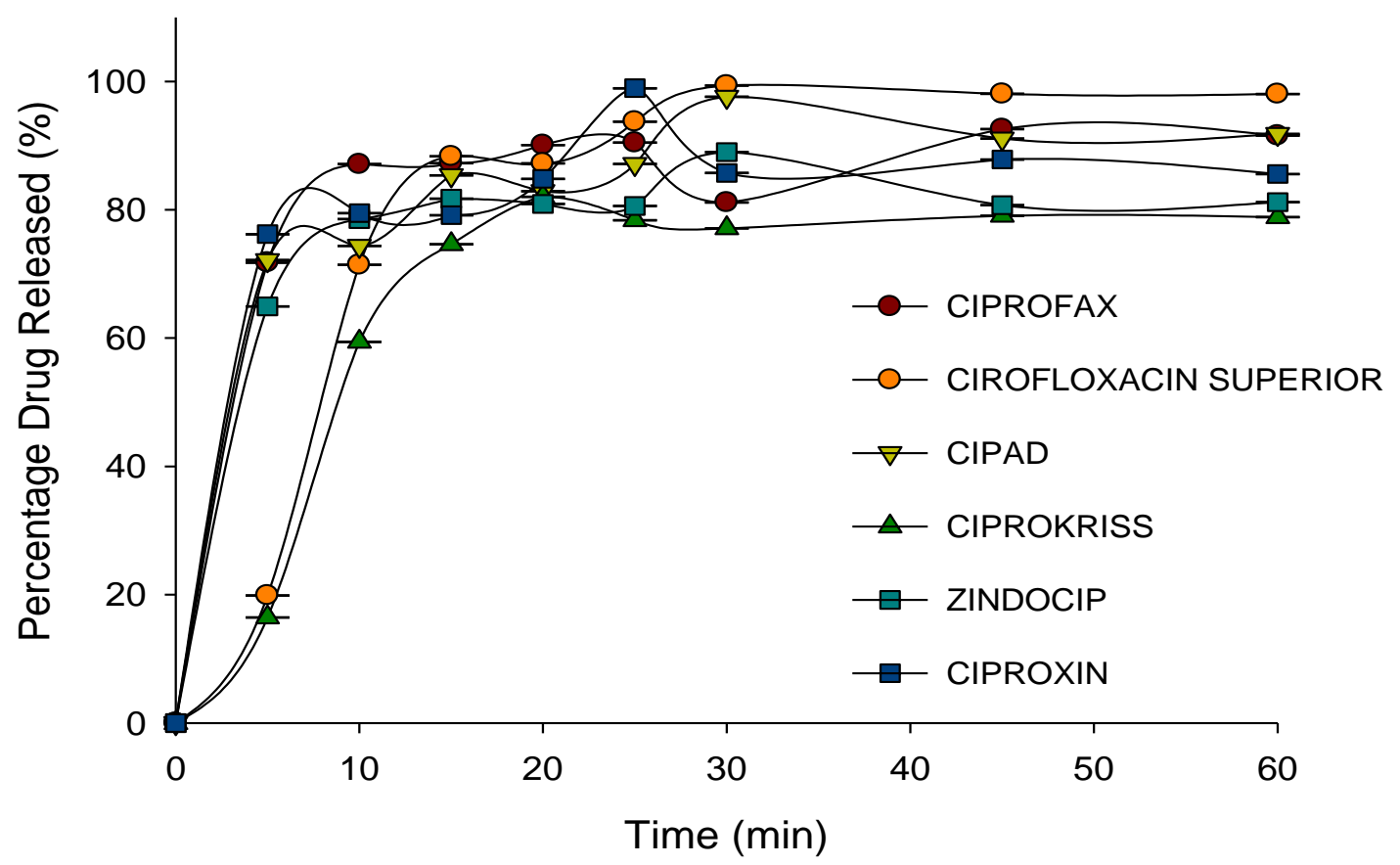

Fig. 11. Percentage Drug Release Profiles of Brands Ciprofax, Ciprofloxacin superior, Cipad, Ciprokriss and Zindocip in Acetate Buffer pH 4.5 in comparision with ciproxin 


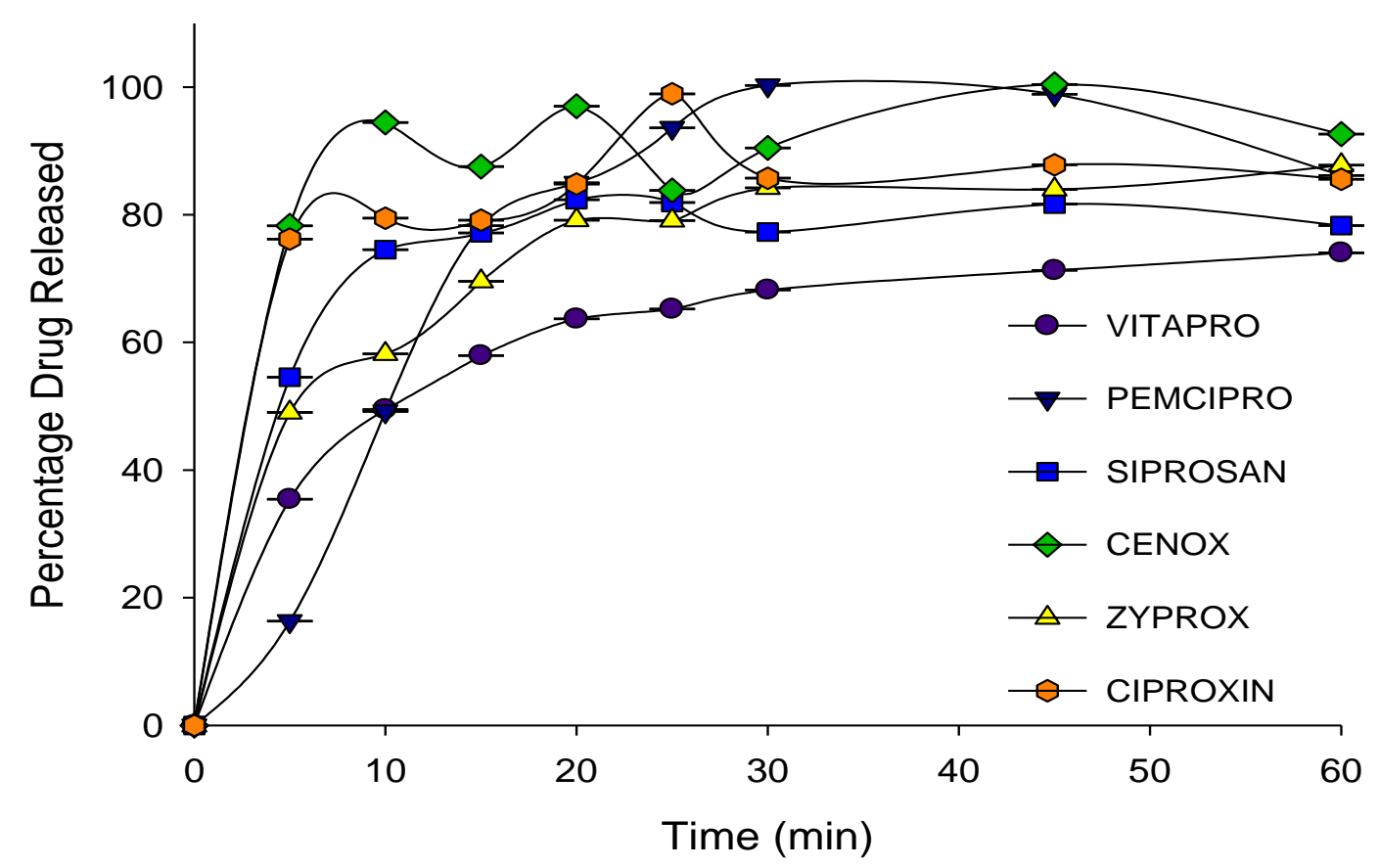

Fig. 12. Percentage Drug Release Profiles of Brands Vitapro, Pemcipro, Siprosan, Cenox and Zyprox in Acetate Buffer $\mathrm{pH} 4.5$ in comparision with ciproxin

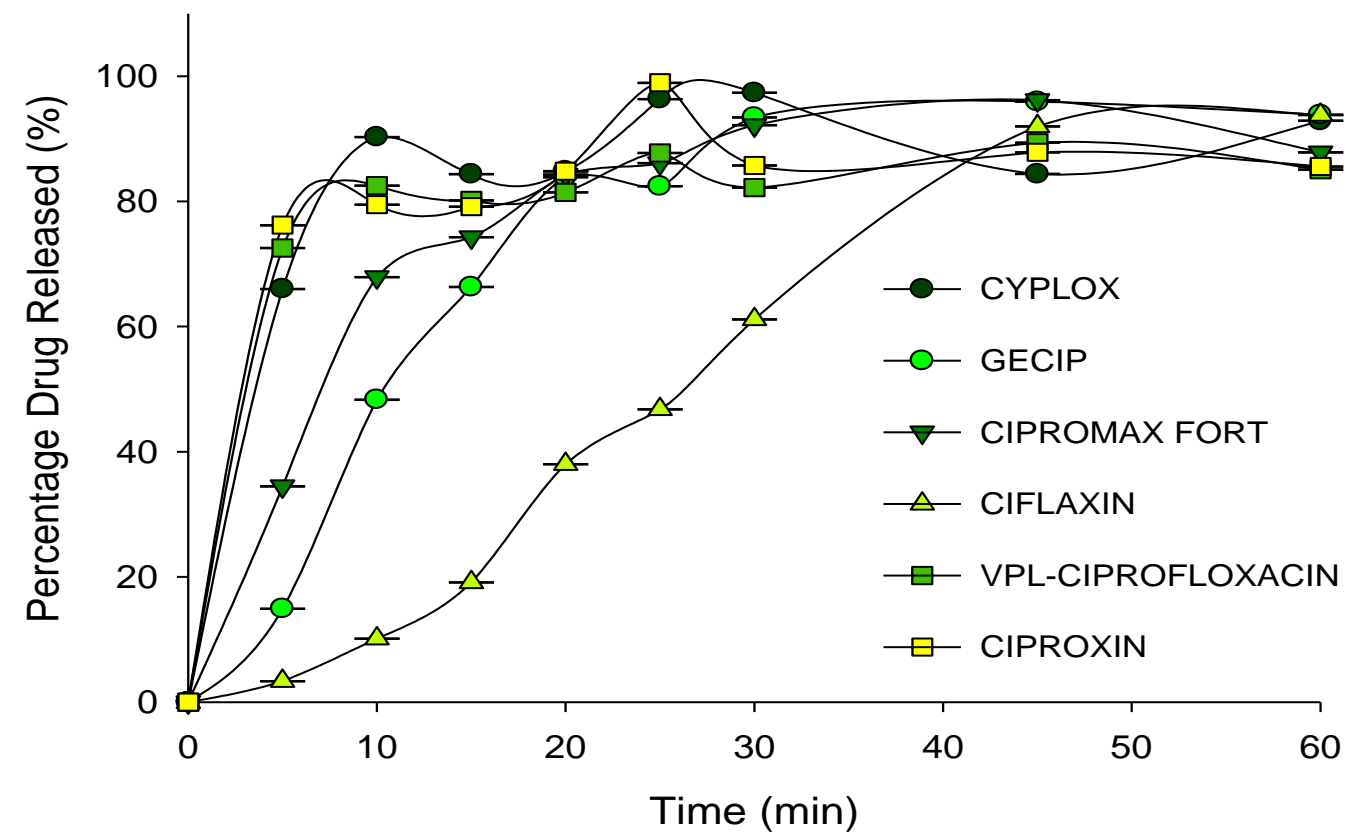

Fig. 13. Percentage Drug Release Profiles of Brands Cyplox, Gecip, Cipromax Fort, Ciflaxin and VPLCiprofloxacin in Acetate Buffer $\mathrm{pH} 4.5$ in comparision with ciproxin 
H.S. Muhammad et al. / J. Pharmacy \& Bioresources 17(2), 208-233 (2020)

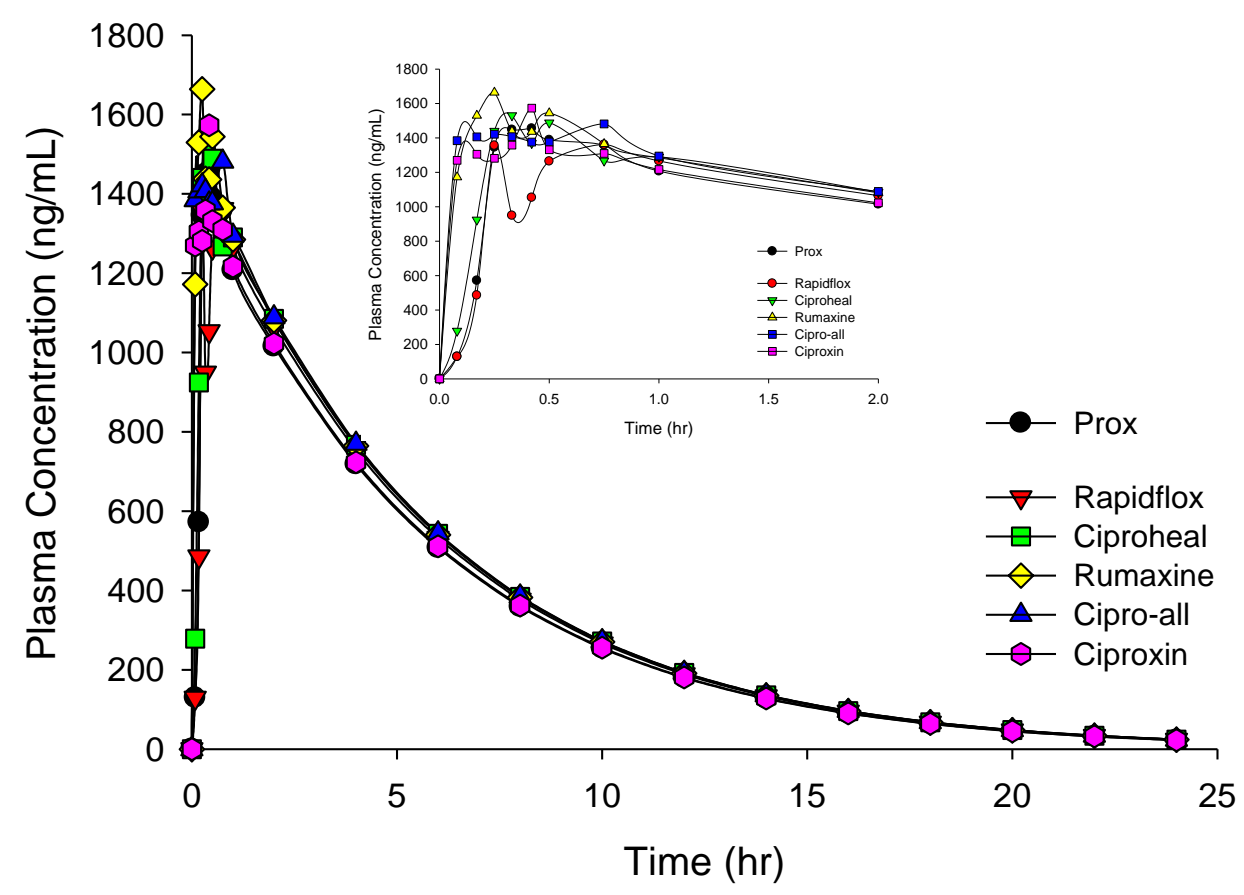

Fig. 16. Predicted plasma concentration time profiles of brands Prox, Rapidflox, Ciproheal, Rumaxine and Cipro-all in in comparision with ciproxin

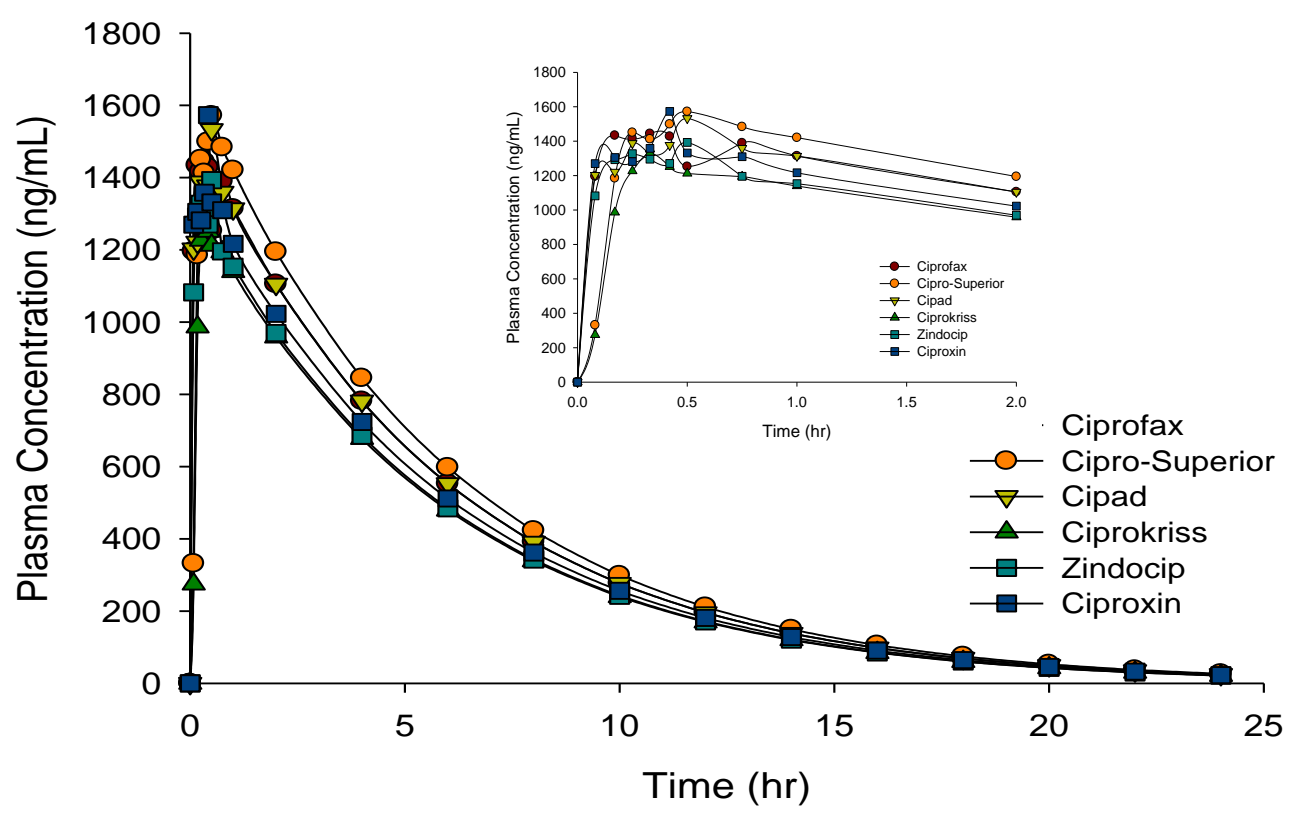

Fig. 17. Predicted plasma concentration time profiles of Brands Ciprofax, Ciprofloxacin superior, Cipad, Ciprokriss and Zindocip in comparision with ciproxin 


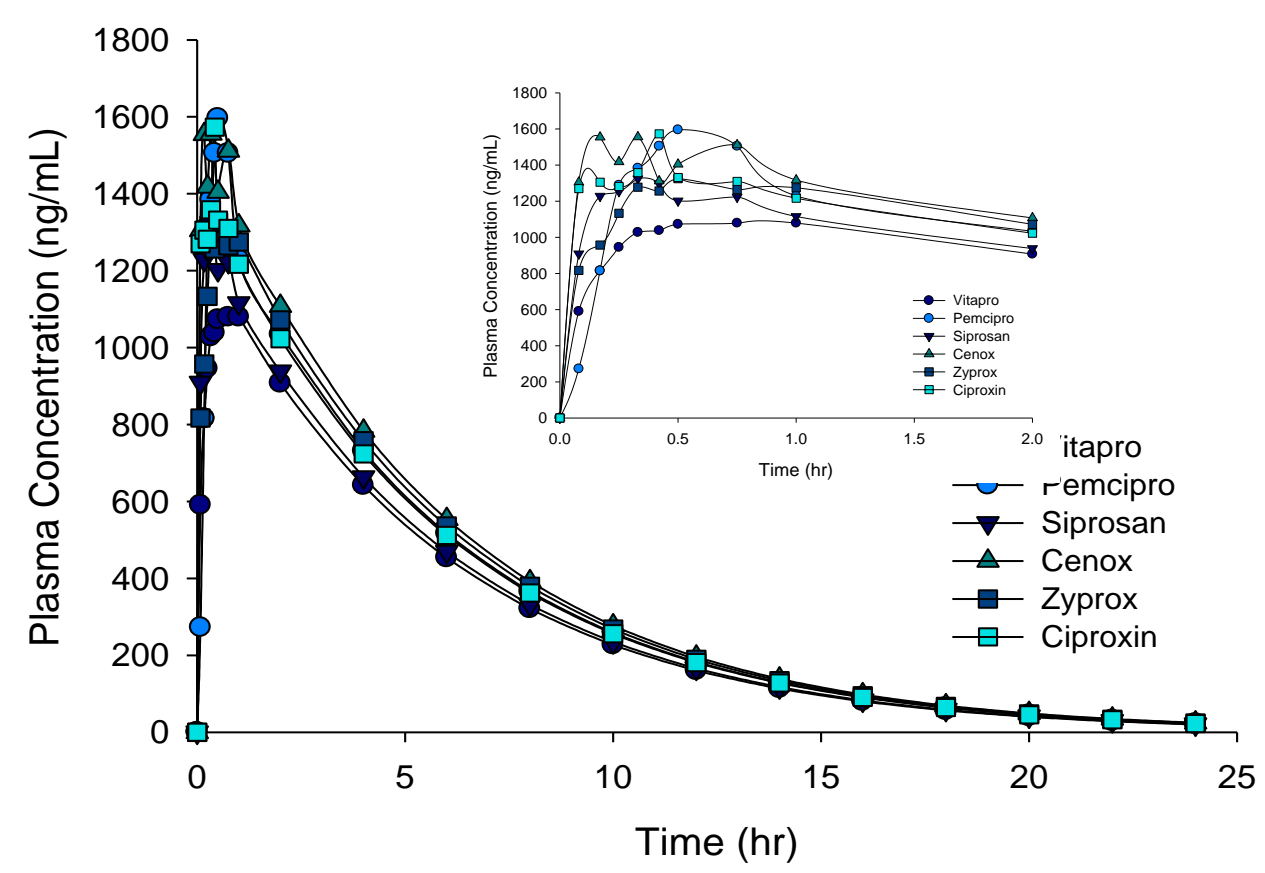

Fig. 18. Predicted plasma concentration time profiles of Brands Vitapro, Pemcipro, Siprosan, Cenox and Zyprox in comparision with ciproxin

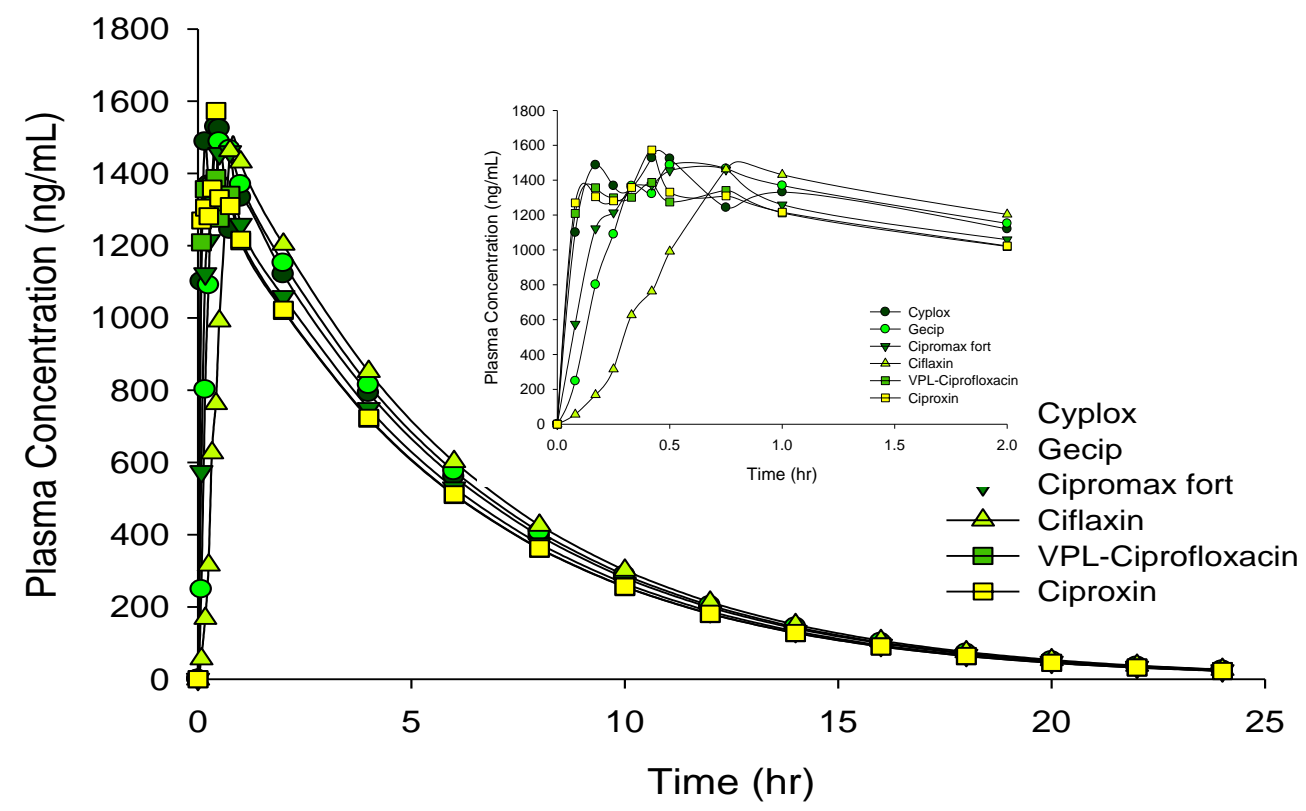

Fig. 19. Predicted plasma concentration time profiles of Brands Cyplox, Gecip, Cipromax Fort, Ciflaxin and VPLCiprofloxacin in comparision with ciproxin 


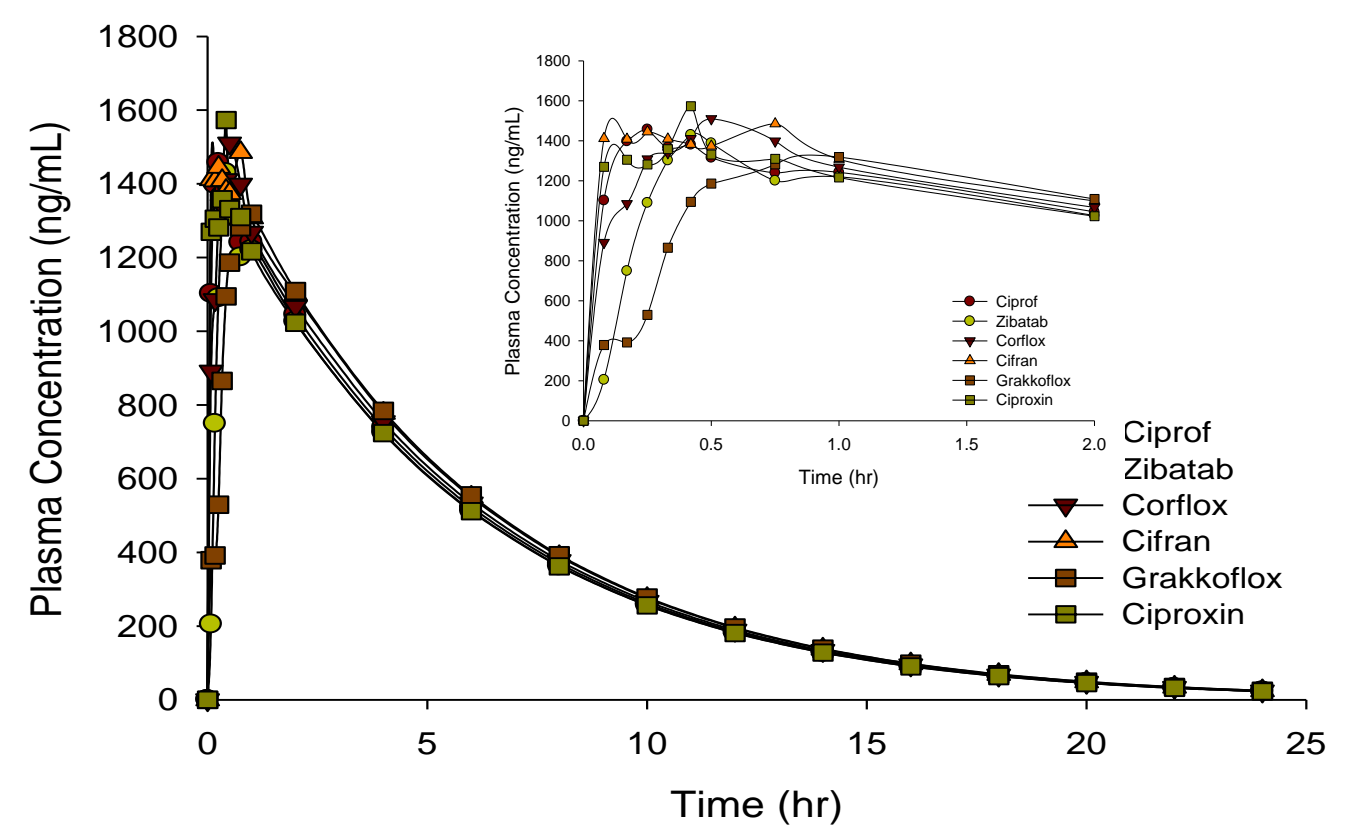

Fig. 20. Predicted plasma concentration time profiles of Brands Ciprof, Zibatab, Corflox, Cifran and Grakkoflox in comparision with ciproxin

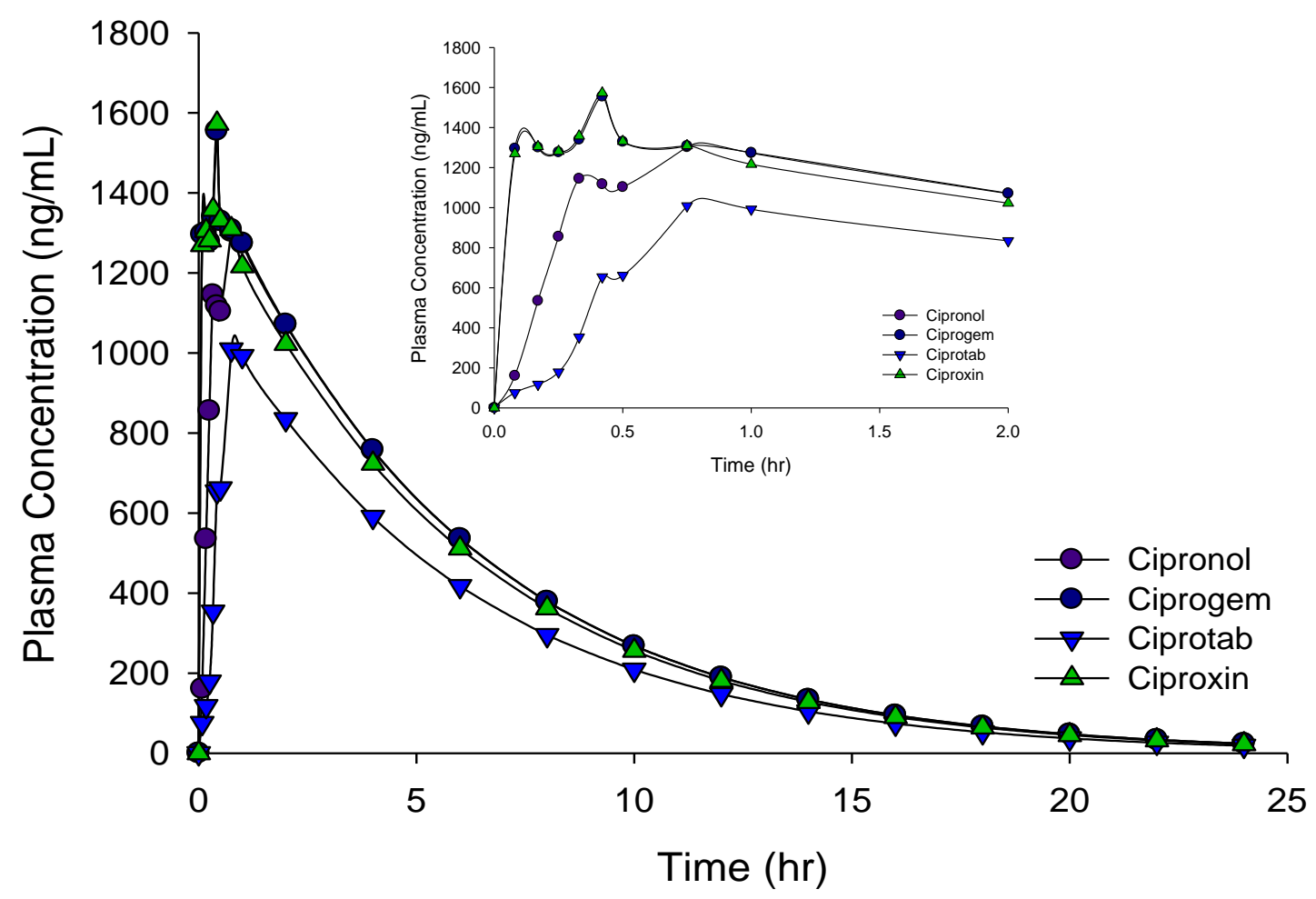

Fig. 21. Predicted plasma concentration time profiles of Brands Cipronol, Ciproxin, Ciprogem and Ciprotab in comparision with ciproxin 
Table 4: Similarity Factor $f_{2}$ and Difference Factor $f_{l}$ for Ciprofloxacin Brands using Ciproxin as the reference

\begin{tabular}{|c|c|c|c|}
\hline S/No & Brands & $\begin{array}{c}\text { Similarity factor } f_{2} \\
(50-100)\end{array}$ & $\begin{array}{c}\text { Difference factor } f_{l} \\
(0-15)\end{array}$ \\
\hline 1 & Prox & 29.28 & 24.08 \\
\hline 2 & Rapidflox & 53.07 & 9.00 \\
\hline 3 & Ciproheal & 47.44 & 9.62 \\
\hline 4 & Rumaxine & 39.15 & 16.26 \\
\hline 5 & Cipro-All & 52.09 & 8.57 \\
\hline 6 & Ciprofax & 37.02 & 17.86 \\
\hline 7 & Cirofloxacin Superior & 35.71 & 22.73 \\
\hline 8 & Cipad & 45.53 & 12.15 \\
\hline 9 & Ciprokriss & 23.37 & 41.92 \\
\hline 10 & Zindocip & 16.38 & 56.95 \\
\hline 11 & Vitapro & 33.24 & 26.14 \\
\hline 12 & Pemcipro & 50.55 & 9.47 \\
\hline 13 & Siprosan & 15.39 & 60.00 \\
\hline 14 & Cenox & 38.64 & 14.53 \\
\hline 15 & Zyprox & 68.77 & 4.62 \\
\hline 16 & Cyplox & 45.25 & 11.36 \\
\hline 17 & Gecip & 25.63 & 33.72 \\
\hline 18 & Cipromax Fort & 63.49 & 5.22 \\
\hline 19 & Ciflaxin & 18.30 & 48.68 \\
\hline 20 & Vpl-Ciprofloxacin & 49.92 & 9.98 \\
\hline 21 & Ciprof & 45.48 & 12.40 \\
\hline 22 & Zibatab & 37.89 & 16.29 \\
\hline 23 & Corflox & 43.38 & 15.61 \\
\hline 24 & Cifran & 51.75 & 8.85 \\
\hline 25 & Grakkoflox & 22.94 & 41.85 \\
\hline 26 & Cipronol & 36.02 & 21.03 \\
\hline 27 & Ciproxin & Ref & Ref \\
\hline 28 & Ciprogem & 67.81 & 3.80 \\
\hline 29 & Ciprotab & 11.52 & 70.19 \\
\hline
\end{tabular}

$f 2=$ Brands in bold failed the $f 2$ test. $f 1=$ Brands in bold failed the $f 1$ test.

Table 5: Similarity Factor $f_{2}$ and Difference Factor $f_{1}$ for Ciprofloxacin Brands using Ciproxin as the Reference

\begin{tabular}{llcc}
\multicolumn{4}{c}{ Brand (Acetate Buffer pH 4.5) } \\
\hline S/No & \multicolumn{1}{c}{$\begin{array}{c}\text { Similarity factor } f_{2} \\
(50-100)\end{array}$} & $\begin{array}{c}\text { Difference factor } f_{1} \\
(0-15)\end{array}$ \\
\hline 1 & Prox & 28.01 & 19.64 \\
2 & Rapidflox & 24.65 & 28.09 \\
3 & Ciproheal & 32.46 & 19.04 \\
4 & Rumaxine & 48.23 & 11.49 \\
5 & Cipro-All & 57.26 & 8.17 \\
6 & Ciprofax & 60.83 & 7.27 \\
7 & Cirofloxacin Superior & 34.34 & 17.34 \\
8 & Cipad & 58.17 & 7.45 \\
9 & Ciprokriss & 32.22 & 19.44 \\
10 & Zindocip & 54.86 & 7.63 \\
11 & Vitapro & 30.72 & 28.39 \\
12 & Pemcipro & 31.66 & 18.11 \\
13 & Siprosan & 49.27 & 10.31 \\
14 & Cenox & 49.79 & 11.39 \\
15 & Zyprox & 42.85 & 13.45 \\
16 & Cyplox & 57.20 & 7.56 \\
17 & Gecip & 30.61 & 21.66 \\
18 & Cipromax Fort & 40.36 & 13.07 \\
19 & Ciflaxin & 16.70 & 49.89 \\
20 & Vpl-Ciprofloxacin & 67.22 & 4.11 \\
21 & Ciprof & 58.76 & 6.57 \\
22 & Zibatab & 30.08 & 20.34
\end{tabular}


H.S. Muhammad et al. / J. Pharmacy \& Bioresources 17(2), 208-233 (2020)

\begin{tabular}{llcc}
23 & Corflox & 49.38 & 9.96 \\
24 & Cifran & 55.95 & 8.74 \\
25 & Grakkoflox & 23.53 & 35.17 \\
26 & Cipronol & 25.28 & 30.29 \\
27 & Ciproxin & Ref & Ref \\
28 & Ciprogem & 88.50 & 1.15 \\
29 & Ciprotab & 13.66 & 62.65 \\
\hline
\end{tabular}

Table 6: Dissolution Efficiency for Ciprofloxacin Brands using Ciproxin as the Reference Brand (Acetate Buffer $\mathrm{pH} 4.5)$

\begin{tabular}{|c|c|c|c|}
\hline S/No & Brands & $\mathrm{DE}(\%)$ & Difference between DEs of reference and test products* \\
\hline 1 & Prox & 72.6 & 9.2 \\
\hline 2 & Rapidflox & 65.7 & 16.1 \\
\hline 3 & Ciproheal & 76.3 & 5.5 \\
\hline 4 & Rumaxine & 88.1 & -6.3 \\
\hline 5 & Cipro-All & 86.8 & -5 \\
\hline 6 & Ciprofax & 83.7 & -1.9 \\
\hline 7 & Cirofloxacin Superior & 83.4 & -1.6 \\
\hline 8 & Cipad & 84.0 & -2.2 \\
\hline 9 & Ciprokriss & 68.4 & 13.4 \\
\hline 10 & Zindocip & 77.4 & 4.4 \\
\hline 11 & Vitapro & 61.1 & 20.7 \\
\hline 12 & Pemcipro & 79.1 & 2.7 \\
\hline 13 & Siprosan & 74.0 & 7.8 \\
\hline 14 & Cenox & 88.5 & -6.7 \\
\hline 15 & Zyprox & 73.9 & 7.9 \\
\hline 16 & Cyplox & 84.1 & -2.3 \\
\hline 17 & Gecip & 69.6 & 12.2 \\
\hline 18 & Cipromax Fort & 79.3 & 2.5 \\
\hline 19 & Ciflaxin & 54.7 & 27.1 \\
\hline 20 & Vpl-Ciprofloxacin & 80.4 & 1.4 \\
\hline 21 & Ciprof & 80.3 & 1.5 \\
\hline 22 & Zibatab & 69.3 & 12.5 \\
\hline 23 & Corflox & 81.3 & 0.5 \\
\hline 24 & Cifran & 87.2 & -5.4 \\
\hline 25 & Grakkoflox & 60.7 & 21.1 \\
\hline 26 & Cipronol & 62.8 & 19 \\
\hline 27 & Ciproxin & 81.8 & 0.0 \\
\hline 28 & Ciprogem & 82.1 & -0.3 \\
\hline 29 & Ciprotab & 37.8 & 44 \\
\hline
\end{tabular}

*The numbers in bold indicate bio-inequivalence

Content assay. Content assay provides an insight into the identity and quality of drug product when specific analytical methods are employed. Concentration of active ingredient below the specification may predispose patients to treatment failure and when above the specification, may lead to adverse drug events. The USP specification for ciprofloxacin tablets is that the tablets should contain ciprofloxacin hydrochloride equivalent to not less than $90 \%$ and not more than $110 \%$ of the labelled amount of ciprofloxacin (500 mg) [19]. Six (6) brands of ciprofloxacin failed the content assay test as shown in Figure 1. These brands are prox, rumaxine, cipro-all, cipro-kriss, pemcipro and cipronol.

Regarding antibiotics, the challenge of drug content being outside specification is not just about treatment failure and adverse drug events but also about development of antimicrobial resistance. Providing subinhibitory doses of antimicrobial agents facilitate the ability of microorganisms to develop resistance to the antimicrobial agents. Sub-inhibitory concentrations provide an environmental condition that play a vital role in the development and spread of antimicrobial resistance [22]. 
Table 7: Predicted pharmacokinetic parameters of the brands of ciprofloxacin

\begin{tabular}{|c|c|c|c|c|c|c|c|c|}
\hline $\mathrm{S} / \mathrm{N}$ & Brands & $\begin{array}{c}\mathrm{C}_{\max } \\
(\mathrm{ng} / \mathrm{mL})\end{array}$ & $\begin{array}{l}T_{\max } \\
(\mathrm{h})\end{array}$ & $\begin{array}{l}\mathrm{T}_{1 / 2} \\
(\mathrm{~h})\end{array}$ & $\begin{array}{c}\text { AUC } \\
(\mathrm{ng} / \mathrm{mL} * \mathrm{~h})\end{array}$ & $\begin{array}{l}\text { MRT } \\
\text { (h) }\end{array}$ & $\begin{array}{c}\mathrm{Vz} / \mathrm{F} \\
(\mathrm{mg}) /(\mathrm{mg} / \mathrm{mL})\end{array}$ & $\begin{array}{c}\mathrm{Cl} / \mathrm{F} \\
(\mathrm{mg}) /(\mathrm{ng} / \mathrm{mL}) / \mathrm{h}\end{array}$ \\
\hline 1 & Prox & 1455.48 & 0.42 & 4.0 & 8030.84 & 5.83 & 0.35 & 0.0613 \\
\hline 2 & Rapidflox & 1361.79 & 0.75 & 4.0 & 8275.08 & 5.92 & 0.34 & 0.0595 \\
\hline 3 & Ciproheal & 1530.90 & 0.33 & 4.0 & 8561.01 & 5.84 & 0.33 & 0.0575 \\
\hline 4 & Rumaxine & 1663.83 & 0.25 & 4.0 & 8707.59 & 5.73 & 0.33 & 0.0565 \\
\hline 5 & Ciproall & 1481.22 & 0.75 & 4.0 & 8745.65 & 5.74 & 0.33 & 0.0563 \\
\hline 6 & Ciprofax & 1443.81 & 0.33 & 4.0 & 8810.74 & 5.78 & 0.33 & 0.0559 \\
\hline 7 & Cipro-Superior & 1572.18 & 0.50 & 4.0 & 9418.34 & 5.85 & 0.30 & 0.0522 \\
\hline 8 & Cipad & 1532.78 & 0.50 & 4.0 & 8952.72 & 5.78 & 0.32 & 0.0559 \\
\hline 9 & Cipro-Kriss & 1332.41 & 0.33 & 4.0 & 7577.98 & 5.83 & 0.37 & 0.0649 \\
\hline 10 & Zindocip & 1392.97 & 0.50 & 4.0 & 7788.38 & 5.74 & 0.37 & 0.0632 \\
\hline 11 & Vitapro & 1079.16 & 1.00 & 4.0 & 7119.19 & 5.87 & 0.40 & 0.0691 \\
\hline 12 & Pemcipro & 1595.86 & 0.50 & 4.0 & 8259.30 & 5.78 & 0.34 & 0.0596 \\
\hline 13 & Siprosan & 1324.33 & 0.33 & 4.0 & 7642.62 & 5.75 & 0.38 & 0.0654 \\
\hline 14 & Cenox & 1555.60 & 0.33 & 4.0 & 8900.00 & 5.74 & 0.32 & 0.0553 \\
\hline 15 & Zyprox & 1324.82 & 0.50 & 4.0 & 8434.76 & 5.85 & 0.34 & 0.0583 \\
\hline 16 & Cyplox & 1528.51 & 0.42 & 4.0 & 8916.56 & 5.79 & 0.32 & 0.0552 \\
\hline 17 & Gecip & 1487.66 & 0.50 & 4.0 & 9014.19 & 5.89 & 0.32 & 0.0546 \\
\hline 18 & Cipromax fort & 1460.44 & 0.75 & 4.0 & 8432.90 & 5.79 & 0.34 & 0.0584 \\
\hline 19 & Ciflaxin & 1463.02 & 0.75 & 4.0 & 9050.30 & 6.11 & 0.31 & 0.0543 \\
\hline 20 & Vpl-Cipro & 1387.07 & 0.42 & 4.0 & 8176.68 & 5.75 & 0.35 & 0.0602 \\
\hline 21 & Ciprof-500 & 1457.32 & 0.25 & 4.0 & 8344.63 & 5.77 & 0.34 & 0.0589 \\
\hline 22 & Zibatab & 1429.72 & 0.42 & 4.0 & 8056.59 & 5.87 & 0.35 & 0.0610 \\
\hline 23 & Corflox & 1509.99 & 0.50 & 4.0 & 8512.54 & 5.77 & 0.33 & 0.0578 \\
\hline 24 & Cifran & 1485.17 & 0.75 & 4.0 & 8824.43 & 5.75 & 0.32 & 0.0557 \\
\hline 25 & Grakkoflox & 1318.74 & 1.00 & 4.0 & 8491.37 & 6.00 & 0.33 & 0.0579 \\
\hline 26 & Cipronol & 1302.9 & 0.75 & 4.0 & 8260.74 & 5.96 & 0.34 & 0.0595 \\
\hline 27 & Ciproxin & 1572.70 & 0.42 & 4.0 & 8220.19 & 5.74 & 0.35 & 0.0599 \\
\hline 28 & Ciprogem & 1554.69 & 0.42 & 4.0 & 8560.00 & 5.77 & 0.33 & 0.0575 \\
\hline 29 & Ciprotab & 1008.83 & 0.75 & 4.0 & 6270.71 & 6.10 & 0.45 & 0.0784 \\
\hline
\end{tabular}

When microorganisms are exposed to subinhibitory concentrations, these have effects on their bacterial physiology and morphology leading to modulation of fitness and pathogenicity traits. The mechanisms of fluoroquinolone resistance include modulation of target, increased efflux (export of a drug out of the microorganism), fluoroquinolone inactivation (by an aminoglycoside Nacetyltransferase), and protection of the target by DNA-binding proteins (known as Qnr) [23]. Assuring quality of antimicrobial agents is one of the strategies that can reduce antimicrobial resistance. Other strategies include patient adherence, removing antimicrobial selective pressure, health promotion and regulation to restrict antimicrobial agents to prescription only drugs.
Microbiological evaluation. A biological or microbiological assay is employed to evaluate both potency and bioactivity of an antimicrobial agent [24]. Quality control of antimicrobial formulations must therefore include antimicrobial potency assay. Agar well diffusion method is a practical and economical method to use. In this study, nine (9) brands of ciprofloxacin failed the potency test (Figure 2) as they were outside the USP specification of content assay (90-110\%). These brands were Ciproheal (74.9\% and 85.8\%), Cipad (89.2\% and $88.7 \%)$, Cipro-Kriss (58.9\% and $65.9 \%)$, Siprosan (88.5\% and 87.0\%), Gecip (65\% and $76.8 \%)$, Zibatab (66.4\% and $89.0 \%)$, Corflox (62.6\% and $76.7 \%)$, Cifran $(73.3 \%$ and $66.1 \%)$ and Grakkoflox (78.5\% and $79.6 \%$ ) indicating $\%$ potency against $P$. aeruginosa and $S$. aureus 
respectively. This microbiological evaluation provides insight to the antimicrobial activity of these brands of ciprofloxacin. This may confirm the clinical observations of the health professionals in hospitals in North-eastern Nigeria. As the brands varied in $\%$ potencies so will their therapeutic efficacies. Indeed, this data may be a guide for the health professionals to make evidence-based decisions on procurement and prescribing. The disparity between the \% potency for some brands for the two test organisms as found in brands ciproheal, cipro-kriss, gecip, zibatab, corflox and cifran ought not to be. The mechanism of action of ciprofloxacin is the same for gram-positive and gram-negative organisms and so the \% potency should be same for both organisms. The disparity may be due to actives/metabolites/impurities which may have affected one organism more than the other, giving exaggerated response.

Test for impurities. Any substance in a formulation other than the API and excipients is an impurity. Limiting the quantity of impurities if not ensuring none is a regulatory requirement as some impurities may be toxic and some may affect the efficacy of APIs. As a result, test for purity and impurity profiling are mandatory to establish biological safety [25]. Impurities may emanate from the API as byproducts of synthesis, excipients, during formulation process and packaging or degraded products on storage. Figure 3 displayed two images as samples of the outcome of test for impurities using TLC. Singles spots were observed in all plates for all brands. All brands had the same Rf values of 0.73 indicating the presence of ciprofloxacin in all the brands. The single spots implied that there were no impurities. While this study indicated no impurities, Kyriacos and coworkers [26] found impurities ethylenediamine, desfluorociprofloxacin and fluoroquinolonic acid - which were not more than $0.2 \%$ and were therefore within limits. This study employed TLC while Kyriacos and co-workers utilized HPLC. It is worthy to note that HPLC has better sensitivity, selectivity, and resolution. In another study, Trefi and colleagues [27] used ${ }^{19} \mathrm{~F}$ and ${ }^{1} \mathrm{H}$ nuclear magnetic resonance (NMR) and DiffusionOrdered ${ }^{1} \mathrm{H}$ NMR Spectroscopy $\left({ }^{1} \mathrm{H}\right.$ NMR DOSY) for impurity profiling of generic ciprofloxacin tablets. Four to twelve fluorinated impurities were detected in all brands tested, two non-fluorinated were detected in seven formulations and degradation product of ciprofloxacin was found in all the formulations tested. Consequently, absence of impurities in this study may suggest that there may be no co-active ingredient which may interfere with the efficacy of ciprofloxacin hydrochloride or be toxic to the patient. It may also suggest that a more sensitive and selective instrument should be used to test for impurities.

In vitro drug release. Aesthetic formulations may appeal to the senses of touch, sight, and taste; however, if they are not able to release the drugs to produce the desired therapeutic effects, they are as good as placebo. The rate of liberation from tablet matrix and rate of release determines the rate and extent of absorption. The rate and extent of absorption determine the minimum inhibitory concentrations (MICs) and minimum bactericidal concentrations (MBCs) which influence therapeutic efficacy of antibiotics. Consequently, dissolution testing which assesses the rate of drug release over time can be employed as a surrogate for bioavailability studies. In vitro drug release studies can be used to predict in vivo absorption giving insight into the liberation and absorption patterns of the formulation. For antibiotics, the optimal dosing should be equal to or greater than the MICs for bacteriostatic drugs and equal to or greater than the MBCs of bactericidal drugs. However, to prevent antimicrobial resistance, bactericidal drugs are preferred. Ciprofloxacin exhibits both bacteriostatic and bactericidal activities depending on concentration the organisms are 
exposed to [28]. The study of release of ciprofloxacin from the formulations gives insight into the rate of liberation from tablet matrices, amount released and invariably, plasma concentration that will be expected from each brand.

In this study, employing dissolution medium, $0.1 \mathrm{~N} \mathrm{HCl}, 9$ of 29 brands released $\geq$ $85 \%$ of the labelled amount in $15 \mathrm{~min}$. These brands are ciproall $(88.8 \%)$, ciprofax $(88.8 \%)$, ciprofloxacin-superior $\quad(106 \%)$, pemcipro (87\%), cenox (89.7\%), cyplox (88.2\%), ciprof $(99.8 \%)$, cifran $(91 \%)$ and ciproxin $(85 \%)$ while 20 brands that released $\geq 80 \%$ of the labelled amount in $30 \mathrm{~min}$ are rapidflox (96.9\%), prox $(92.2 \%)$, ciproheal $(97.1 \%)$, rumaxine $(82.8 \%)$, ciproall $(88.5 \%)$, ciprofax (88.5\%), ciprofloxacin-superior $(85.2 \%)$, cipad (83.2\%), pemcipro (80\%), cenox (99.4\%), zyprox (99.9\%), cyplox (99.3\%), cipromax fort (96.2\%), vpl-ciprofloxacin (92.4\%), ciprof (99.8\%), zibatab (92\%), corflox $(82.4 \%)$, cifran $(88.3 \%)$, ciproxin $(93.1 \%)$ and ciprogem (92.8\%). However, 9 brands, ciprokriss (64\%), zindocip (39\%), vitapro (78\%), siprosan (37\%), gecip (74.9\%), ciflaxin $(64.9 \%)$, grakkoflox $(60.9 \%)$, cipronol $(60.9 \%)$, and ciprotab (27.6\%) failed to release $80 \%$ of the labelled amount in $30 \mathrm{~min}$.

When acetate buffer $\mathrm{pH} 4.5$ was used, 9 brands, ciproall $(86.9 \%)$, ciprofax $(86.3 \%)$, ciproheal $(86.9 \%)$, rumaxine $(101.1 \%)$, cipad $(85 \%)$, ciprofloxacin-superior $(87.7 \%)$, cenox $(86.5 \%)$, ciprof $(88.8 \%)$, and cifran $(88 \%)$ released $\geq 85 \%$ of the labelled amount in 15 min. Then, 20 brands, prox $(85.8 \%)$, ciproheal (92\%), rumaxine (96\%), ciproall (86\%), ciprofloxacin- superior $(97.2 \%)$, cipad (95.3\%), zindocip (86.8\%), pemcipro $(98 \%)$, cenox $(87 \%)$, zyprox (82\%), cyplox (94\%), gecip $(91 \%)$, cipromax fort $(90.1 \%)$, vplciprofloxacin $(85 \%)$, ciprof $(82 \%)$, zibatab $(85 \%)$, corflox $(93 \%)$, cifran $(86 \%)$, ciproxin $(83 \%)$ and ciprogem $(83 \%)$ released $\geq 80 \%$ of the labelled amount in $30 \mathrm{~min}$. However, ciprokriss $(75.3 \%)$, rapidflox $(77.2 \%)$, ciprofax (78\%), vitapro $(66 \%)$, siprosan $(75 \%)$, ciflaxin $(60.1 \%)$, grakkoflox $(72 \%)$, cipronol $(68 \%)$, and ciprotab $(40.3 \%)$ failed to release $80 \%$ in $30 \mathrm{~min}$. It may be worthy to note that some brands such as zindocip performed significantly better at higher $\mathrm{pH}$ indicating that some formulations may be $\mathrm{pH}$ sensitive thereby slightly or significanlty modulating the rate of release of ciprofloxacin. Excipients can affect the rate of drug release and invariably, the rate and extent of absorption.

For high solubility active pharmaceutical ingredient formulated as immediate release oral dosage forms, the dissolution criterion is $\mathrm{Q}$ (quantity) $=80 \%$ in $30 \mathrm{~min}$ [29]. In each medium (pH 1.2 and 4.5), 20 brands met this criterion, however, 7 brands, ciprokriss, vitapro, siprosan, ciflaxin, grakkoflox, cipronol and ciprotab failed to meet the dissolution criterion in both media.

FDA Guidance for Industry, Waiver of In Vivo Bioavailability and Bioequivalence Studies for Immediate-Release (IR) Solid Oral Dosage Forms states that a product is rapidly dissolving when $\geq 85 \%$ of the labelled active pharmaceutical ingredient dissolves in $0.1 \mathrm{~N}$ $\mathrm{HCl}, \mathrm{pH} 4.5$ and $\mathrm{pH} 6.8$ media within $30 \mathrm{~min}$ [30]. Eighteen (18) brands (prox, ciproheal, rumaxine, cipro-all, ciprofax, cipro-superior, cipad, pemcipro, cenox, cyplox, cipromax fort, vpl-ciprofloxacin, ciprof, zibtab, corflox, cifran, ciprogem and ciproxin) suggest they are rapidly dissolving as $\geq 85 \%$ of the labelled API dissolved in both $0.1 \mathrm{~N} \mathrm{HCl}$ and $\mathrm{pH} 4.5$ in $30 \mathrm{~min}$. In addition, an IR solid dosage form is very rapidly dissolving when $\geq 85 \%$ of the labelled active pharmaceutical ingredient dissolves in $0.1 \mathrm{~N} \mathrm{HCl}, \mathrm{pH} 4.5$ and $\mathrm{pH} 6.8$ within $15 \mathrm{~min}$. Six (6) brands, rumaxine, ciproall, ciprofax, cenox, ciprof and cifran suggest rapid dissolution as $\geq 85 \%$ of the labelled API dissolved in both $0.1 \mathrm{~N} \mathrm{HCl}$ and $\mathrm{pH} 4.5$ media in $15 \mathrm{~min}$.

The dissolution profiles in $\mathrm{pH} 6.8$ was not presented as the dissolution of ciprofloxacin in 
pH 6.8 was $\leq 35 \%$. Oishi and co-workers [31] obtained similar lower drug release $(37.17 \%)$ in $\mathrm{pH}$ 6.8. Fluoroquinolones such as ciprofloxacin are zwitterionic comprising two proton-binding sites and displays a U-shaped $\mathrm{pH}$ solubility profile [32]. Ciprofloxacin is highly soluble at $\mathrm{pH}$ less than 5 and above 10 with limited solubility close to neutral ( $\mathrm{pH} 7)$.

Ciprofloxacin has been classified into the 4 classes of Biopharmaceutical Classification System (BCS) by various studies [26, 32-39]. The common class ciprofloxacin is attributed to is Class III (high solubility, low permeability). However, Hansmann and coworkers [37] suggest that ciprofloxacin behaves like a Class I (high solubility, high permeability) drug in vivo. The BCS class changes could be due to the sensitivity of the drug to the excipients used in formulation [39]. Consequently, the FDA biowaiver guidelines advocates that for class III, the test product must contain the same excipients as the reference for a biowaiver to be scientifically justified [30]. This was not the case for all brands.

Mathematical models, similarity and difference factors were employed to determine the bioequivalence between the generic brands and innovator brand, ciproxin. The similarity factor $\left(f_{2}\right)$ is a logarithmic reciprocal square root transformation of the sum of squared error and measures the similarity in the percent dissolution between the two curves while the difference factor $\left(f_{l}\right)$ is the difference in percentage between two curves at each point and measures the relative error between the two curves [1]. Similarity factor $\left(f_{2}\right)$ is recommended by US Food Drug and Administration, and European Medicines Agency (EMA) for comparing similarity between two or more dissolution profiles and invariably for determining bioequivalence.

Tables 4 and 5 show the data for similarity factor $\left(f_{2}\right)$ and difference factor $\left(f_{1}\right)$ in $0.1 \mathrm{~N}$ $\mathrm{HCl}$ and $\mathrm{pH}$ 4.5, respectively. For a test product to be said to be bioequivalent to the reference or innovator product, similarity factor $\left(f_{2}\right)$ should be between 50 and 100 and difference factor $\left(f_{1}\right)$ should be between 0 and 15. Dissolution efficiency (DE) was also used to compare similarity and determine bioequivalence in order to have at least three comparison approaches. Dissolution efficiency is described as the area under the dissolutiontime curve expressed as a percentage of the dissolution curve at maximum dissolution y100 over the same time range. The innovator brand and the generic product can be said to be bioequivalent if the difference between their DEs is within appropriate limits $( \pm 10 \%)$ [1]. Dissolution efficiency was only calculated using dissolution profiles obtained in medium $\mathrm{pH} 4.5$ because this is the $\mathrm{pH}$ closer to the absorption window/site of ciprofloxacin.

In $0.1 \mathrm{~N} \mathrm{HCl}$, seven brands, rapidflox, cipro-all, pemcipro, zyprox, cipromax fort, cifran and ciprogem were bioequivalent to the innovator brand, ciproxin using $f_{1}$ and $f_{2}$ (Table 4). Six brands, ciproheal, cipad, cenox, cyplox, vpl-ciprofloxacin and ciprof were bioequivalent with $f_{l}$ and bio-inequivalent with $f_{2}$. In $\mathrm{pH} 4.5$, nine brands, cipro-all, ciprofax, cipad, zindocip, cyplox, vpl-ciprofloxacin, ciprof, cifran and ciprogem were bioequivalent using $f_{1}$ and $f_{2}$ (Table 5). Six brands, rumaxine, siprosan, cenox, zyprox, cipromax fort and corflox were bioequivalent with $f_{l}$ and bioinequivalent with $f_{2}$. Nineteen brands were bioequivalent to ciproxin using DE alone while rapidflox, ciprokriss, vitapro, gecip, ciflaxin, zibatab, grakkoflox, cipronol and ciprotab were not bioequivalent (Table 6). Eight brands, ciprokriss, vitapro, gecip, ciflaxin, zibatab, grakkoflox, cipronol and ciprotab were bioinequivalent using the three models, similarity factor $\left(f_{2}\right)$, and difference factor $\left(f_{1}\right)$ in the two media and dissolution efficiency (DE) in $\mathrm{pH}$ 4.5. Only three brands, cipro-all, cifran and ciprogem were found to be bioequivalent to the innovator brand, ciproxin using the three models, similarity factor $\left(f_{2}\right)$, and difference factor $\left(f_{l}\right)$ in the two media and dissolution 
efficiency in $\mathrm{pH} 4.5$. These three brands may confidently be used interchangeably with the innovator brand, ciproxin. Bio-inequivalence may be caused by excipients or manufacturing process/variables.

Predicted in vivo absorption. Dissolution $\mathrm{pH}$ data chosen for convolution to determine plasma concentration-time curve (Figures $16-$ 21) and pharmacokinetic data was those of $\mathrm{pH}$ 4.5 as the main absorption site for ciprofloxacin is the duodenum and jejunum. $\mathrm{pH}$ range observed in the duodenum is from 4.20 to 8.20 .

The predicted pharmacokinetic parameters for the various brands of ciprofloxacin are shown in Table 7. Maximum plasma concentration, $\mathrm{C}_{\max }$ for the various brands was from 1008 (ciprotab) to $1663.88 \mathrm{ng} / \mathrm{mL}$ (rumaxine); time to maximum plasma concentration, $\mathrm{t}_{\max }$ was from 0.25 (ciprof-500, rumaxine) to $1 \mathrm{~h}$ (grakkoflo, vitapro); $\mathrm{t}_{1 / 2}$ was $4 \mathrm{~h}$ for all; area under the concentration time curve, AUC was from 6270.71 (ciprotab) to $9418.34 \mathrm{ng} / \mathrm{mL}^{*} \mathrm{~h}$ and apparent volume of distribution, $\mathrm{Vz} / \mathrm{F}$, was from 0.30 (ciprosuperior) to $0.45 \mathrm{mg} /(\mathrm{mg} / \mathrm{mL})$ (ciprotab). The predicted $\mathrm{C}_{\max }, \mathrm{t}_{\max }, \mathrm{AUC}$ and $\mathrm{Vz} / \mathrm{F}$ of innovator brand, ciproxin were $1572.7 \mathrm{ng} / \mathrm{mL}$, $0.4 \mathrm{~h}, 8220.19 \mathrm{ng} / \mathrm{mL} * \mathrm{~h}$ and $0.35 \mathrm{mg} /(\mathrm{mg} / \mathrm{mL})$ respectively. The pharmacokinetic data of some brands indicate that absorption will be rapid, ciprofloxacin will be liberated from the tablets and achieve maximum plasma concentration in $\leq 1 \mathrm{~h}$. Brands such as ciprotab, vitapro, cipronol, grakkflox amongst other may need to be reformulated to produce pharmacokinetic data comparable to that of the innovator brand, ciproxin to ensure bactericidal action.

The in vivo studies on ciprofloxacin collaborates with the predicted data in this study such as $t_{1 / 2}$ range from $3-6 \mathrm{~h}$ and $\mathrm{t}_{\max } \leq$ $1 \mathrm{~h} \mathrm{[40-42].} \mathrm{Lubasch} \mathrm{and} \mathrm{co-workers'} \mathrm{[43]} \mathrm{in}$ vivo study on ciprofloxacin $\left(\mathrm{C}_{\max },-1500 \pm 430\right.$ $\mathrm{ng} / \mathrm{mL} ; \mathrm{t}_{\max },-0.78 \pm 0.33 \mathrm{~h}$ and MRT $-5.8 \pm$ 0.94 ) and newer generation quinolones collaborates with some of the predicted pharmacokinetic data in this study. These in vivo studies confirm that pharmacokinetics of drugs can be simulated using in vitro drug release data. Predicting in vivo absorption (plasma drug concentration-time profiles) from in vitro drug release data required inputting known ciprofloxacin parameters volume of distribution $(3 \mathrm{~L} / \mathrm{Kg})$, half-life $(4 \mathrm{~h})$ and oral bioavailability $(0.70)$ obtained from FDA published data [44]. These parameters are inherent in the drug and are not influenced by the formulation. Predicting in vivo absorption from in vitro drug release can be used to avert clinical failure as the product developer can have a prior insight into the liberation and absorption of the formulation. Should the formulation not produce the desired plasma concentration and area under the time curve that can elicit therapeutic response, the product developer can reformulate. Consequently, in vivo simulation does not only validate the in vitro drug release data but also provides some ethical and economic benefits such reduction in cost of product development [45]. The pharmacokinetic parameters were obtained from the non-compartmental analysis of the predicted plasma drug concentration-time profiles using PKsolver, an add-in to Microsoft excel.

Ciprofloxacin is a widely used fluoroquinolones in clinical settings displaying varying clinical success against organisms. The MICs for broad spectrum clinical success against bacteria are from 0.08 to $1.0 \mathrm{ug} / \mathrm{mL}$; higher MICs $(0.5-1.0 \mathrm{ug} / \mathrm{mL})$ are for species such as Pseudomonas, staphylococcus and susceptible S. pneumoniae [46]. It is envisaged that $500 \mathrm{mg}$ dose should achieve the MIC range. Clinical failure to antibiotics includes factors such as host defences, the bacterium and its susceptibility and the concentration profile of the antibiotic. However, most treatment failures are due to antibiotic concentration dependent outcomes such as MIC and AUC. 
The manufacturer or the marketer who receives marketing authorization is responsible for continuous monitoring of the safety of her product(s) in the market, for informing the authorities of possible changes that may affect the marketing authorization and for ensuring the updating of product information in their territories of operation [47]. The clinical pharmacist should report not just adverse drug reactions and medication errors, but also quality issues relating to medicines. Poor quality medicines are a threat to the patients and the health systems. Giving attention to quality issues can prevent adverse drug reactions associated with poor quality medicines and some drug-related problems.

Conclusion. The pharmaceutical integrity of all drugs is of utmost importance, to ensure safe and effective drug therapy. As a result, standardization is necessary to ensure uniformity with compendia such as British pharmacopoeia (B.P), and United States pharmacopoeia (U.S.P) as guides. Pharmaceutical quality assessment of twentynine (29) different brands of ciprofloxacin were undertaken. The inability of some of the brands not to meet the specifications of compendia makes the concerns for the study very germane. The varied potencies of the various brands translate to different therapeutic results, hence making generic substitutions inappropriate. The effects of poor pharmaceutical quality ciprofloxacin in the market cannot be over emphasized, as it is one of the most widely used antibiotics capable of decreasing both morbidity and mortality rates in Africa. There is an urgent need to scale up quality control monitoring at the points of manufacturing and importation, as well as post-market surveys. The post-market survey scale-up can be achieved through partnerships with universities and other tertiary institutions, by equipping their laboratories to standards, where these assays can be carried out. In addition, hospitals in the country can be encouraged to create mini pharmaceutical laboratories within the pharmacy departments for quick quality assessment. This study is a clarion call for all stakeholders to get involved and ensure the safety and potency of drugs in the market.

\section{REFERENCES}

1. Ngwuluka NC, Lawal K, Olorunfemi PO, Ochekpe NA. Post-market in vitro bioequivalence study of six brands of ciprofloxacin tablets/caplets in Jos, Nigeria. Scientific Research and Essays. 2009; 4(4):298-305.

2. Ochekpe N, Bello C, Ngwuluka N, Abubakar M, Mustapha B, Adegoke O. An assessment of the compliance of some essential drugs in Nigeria to pharmacopoeial specifications. Journal of Pharmacy \& Bioresources. 2006; 3(1):7-11.

3. Ochekpe N, Ngwuluka N, Owolayo H, Fashedemi T. Dissolution profiles of three brands of Lamivudine and Zidovudine combinations in the Nigerian market. Dissolution Technologies. 2006; 13(4):12-17.

4. Ochekpe N, Ngwuluka N, Agbowuro A, Obodozie O. Dissolution profiles of twelve brands of sulphadoxine pyrimethamine in the Nigerian market. Dissolution Technologies 2012; 19(1):59-64.

5. Kovacs S, Hawes SE, Maley SN, Mosites E, Wong L, Stergachis A. Technologies for detecting falsified and substandard drugs in low and middle-income countries. PLoS One. 2014; 9(3):e90601.

6. Glass BD. Counterfeit drugs and medical devices in developing countries. Research and Reports in Tropical Medicine. 2014; 201411-22.

7. Nayyar GM, Breman JG, Newton PN, Herrington J. Poor-quality antimalarial drugs in southeast Asia and sub-Saharan Africa. The Lancet infectious diseases. 2012; 12(6):488-496.

8. WHO (2011) Substandard/Spurious/FalselyLabelled/ Falsified/Counterfeit Medical Products. Available via https://apps.who.int/gb/sf/pdf_files/A64_16-en.pdf Accessed 11/11/2019.

9. Renschler JP, Walters KM, Newton PN, Laxminarayan R. Estimated Under-Five Deaths Associated with Poor-Quality Antimalarials in SubSaharan Africa. The American Journal of Tropical Medicine and Hygiene. 2015;92(6_Suppl):119-126.

10. Alomi YA, Kamal E. National Drug Quality Reporting System at Ministry of Health in Saudi Arabia. J Pharmacovigilance. 2016; 4(3):208. 
11. NAFDAC (2020) NAFDAC Registered Products Database: Ciprofloxacin. Available via https://www.nafdac.gov.ng/our-services/registeredproducts/ Accessed 13/05/2020.

12. Osadebe PO, Esimone OC, Akabogu IC. An empirical assessment of the possibility of interchangeability between multisource ciprofloxacin hydrochloride tablets marketed in Nigeria. Boll Chim Farm. 2003; 142(8):352-356.

13. Adegbolagun O, Olalade $\mathrm{O}$, Osumah S. Comparative evaluation of the biopharmaceutical and chemical equivalence of some commercially available brands of ciprofloxacin hydrochloride tablets. Tropical journal of pharmaceutical research. 2007; 6(3):737745 .

14. Okonkwo TJ, Afieroho EO, Odigwe A, Osadebe PO. Assessment of the quality control parameters of five brands of ciprofloxacin hydrochloride caplets in Nigeria. J Pharm Biores. 2009; 3(2):83-88.

15. Akpabio E, Jackson C, Ugwu C, Etim M, Udofia M. Quality control and in vitro bioequivalence studies on four brands of ciprofloxacin tablets commonly sold in Uyo Metropolis, Nigeria. J Chem Pharm Res. 2011; 3(3):734-741.

16. Osonwa Uduma E, Agboke Ayodeji A, Amadi Rosemary C, Okorie O, Opurum Christian C. Bioequivalence studies on some selected brands of ciprofloxacin hydrochloride tablets in the Nigerian market with ciproflox $®$ as innovator brand. Journal of applied pharmaceutical science. 2011; 1(06):80-84.

17. Osonwa UE, Abali SO, Chukwu KI, Udensi KE. Quality Assessment of Fifteen Different Brands of Ciprofloxacin Hydrochloride Tablets Marketed in Anambra. African Journal of Pharmaceutical Research \& Development. 2016; 8(1):1-8.

18. Joda A, Tayo F, Aina B. Quality assessment of ciprofloxacin tablets obtained from community pharmacies in Lagos, Nigeria. Ife Journal of Science. 2018; 20(1):155-168.

19. The United States Pharmacopeia, USP 29/The National Formulary, NF 24;2006. United States Pharmacopeial Convention. Rockville, MD.

20. Mu'az J, Gazali L, Sadiq G, Tom G. Comparative in vitro evaluation of the pharmaceutical and chemical equivalence of multi-source generic ciprofloxacin hydrochloride tablets around Maiduguri metropolitan area. Nigerian Journal of Pharmaceutical Sciences. 2009; 8(2):102-106.

21. Anah VU, Ebong AS, Charles GE, Esenam FD, Ukpanah II, Essien AA, et al. Quantitative and qualitative analysis of some brands of ciprofloxacin tablets sold in Uyo metropolis, Akwa Ibom State, Nigeria. Nigerian Journal of Pharmaceutical and Applied Science Research. 2019; 8(3):15-22.

22. Sinel C, Cacaci M, Meignen P, Guerin F, Davies BW, Sanguinetti M, et al. Subinhibitory Concentrations of Ciprofloxacin Enhance Antimicrobial Resistance and Pathogenicity of Enterococcus faecium. Antimicrob Agents Chemother. 2017; 61(5):10.1128/AAC.02763-16.

23. Holmes AH, Moore LS, Sundsfjord A, Steinbakk M, Regmi S, Karkey A, et al. Understanding the mechanisms and drivers of antimicrobial resistance. The Lancet. 2016; 387(10014):176-187.

24. Dafale NA, Semwal UP, Rajput RK, Singh G. Selection of appropriate analytical tools to determine the potency and bioactivity of antibiotics and antibiotic resistance. Journal of pharmaceutical analysis. 2016; 6(4):207-213.

25. Pilaniya K, Chandrawanshi HK, Pilaniya U, Manchandani P, Jain P, Singh N. Recent trends in the impurity profile of pharmaceuticals. J Adv Pharm Technol Res. 2010; 1(3):302-310.

26. Kyriacos SB, Boukarim C, Safi W, Mroueh M, Maroun AB, El-Khoury G, et al. In vitro testing of ciprofloxacin formulations and preliminary study on BCS biowaiver. J Food Drug Anal. 2009; 17(2):7884.

27. Trefi S, Gilard V, Malet-Martino M, Martino R. Generic ciprofloxacin tablets contain the stated amount of drug and different impurity profiles: A 19F, $1 \mathrm{H}$ and DOSY NMR analysis. J Pharm Biomed Anal. 2007; 44(3):743-754.

28. Silva F, Lourenço O, Queiroz JA, Domingues FC. Bacteriostatic versus bactericidal activity of ciprofloxacin in Escherichia coli assessed by flow cytometry using a novel far-red dye. J Antibiot. 2011; 64(4):321-325.

29. US Food and Drug Administration. Guidance for industry, Dissolution Testing and Acceptance Criteria for Immediate-Release Solid Oral Dosage Form Drug Products Containing High Solubility Drug Substances. 2018. Available via https://www.fda.gov/media/92988/download Accessed 11/11 2019.

30. US Food and Drug Administration. Guidance for Industry, Waiver of in vivo bioavailability and bioequivalence studies for immediate release solid oral dosage forms based on a biopharmaceutics classification system. 2017. Available via https://www.fda.gov/media/70963/download

Accessed 11/11 2019. 
31. Oishi TS, Haque MA, Dewan I, Islam SA. Comparative in vitro dissolution study of some ciprofloxacin generic tablets under biowaiver conditions by RP-HPLC. Int.J.Pharm.Sci.Res. 2011; 2(12):3129-3135.

32. Olivera M, Manzo R, Junginger H, Midha K, Shah V, Stavchansky S, et al. Biowaiver monographs for immediate release solid oral dosage forms: Ciprofloxacin hydrochloride. J Pharm Sci. 2011; 100(1):22-33.

33. WHO. Proposal to waive in vivo bioequivalence requirements for WHO Model List of Essential Medicines immediate-release, solid oral dosage forms. WHO Tech Rep Ser. 2006;(937):391-437.

34. Hanafy AF. In-vitro bioequivalence, physicochemical and economic benefits study for marketed innovator and generic ciprofloxacin hydrochloride tablets in Saudi Arabia. Journal of Applied Pharmaceutical Science. 2016; 6(09):063068.

35. Fahmy S, Abu-Gharbieh E. In vitro dissolution and in vivo bioavailability of six brands of ciprofloxacin tablets administered in rabbits and their pharmacokinetic modeling. Biomed Res Int. 2014; 2014:590848.

36. Kasim NA, Whitehouse M, Ramachandran C, Bermejo $\mathrm{M}$, Lennernäs $\mathrm{H}$, Hussain $\mathrm{AS}$, et al. Molecular properties of WHO essential drugs and provisional biopharmaceutical classification. Molecular pharmaceutics. 2004; 1(1):85-96.

37. Hansmann S, Miyaji Y, Dressman J. An in silico approach to determine challenges in the bioavailability of ciprofloxacin, a poorly soluble weak base with borderline solubility and permeability characteristics. European Journal of Pharmaceutics and Biopharmaceutics. 2018; 122:186-196.

38. Bhattacharya S, Prajapati BG. Formulation, design and development of ciprofloxacin hydrochloride floating bioadhesive tablet. e-Journal of Science \& Technology. 2017; 12(3):55-76.

39. delMoral-Sanchez J, Gonzalez-Alvarez I, GonzalezAlvarez M, Navarro A, Bermejo M. Classification of WHO Essential Oral Medicines for Children
Applying a Provisional Pediatric Biopharmaceutics Classification System. Pharmaceutics. 2019; 11(11):567.

40. Hoffken G, Lode H, Prinzing C, Borner K, Koeppe P. Pharmacokinetics of ciprofloxacin after oral and parenteral administration. Antimicrob Agents Chemother. 1985; 27(3):375-379.

41. Bergan T, Thorsteinsson SB, Solberg R, Bjornskau L, Kolstad IM, Johnsen S. Pharmacokinetics of ciprofloxacin: intravenous and increasing oral doses. Am J Med. 1987; 82(4A):97-102.

42. Lettieri JT, Rogge MC, Kaiser L, Echols RM, Heller AH. Pharmacokinetic profiles of ciprofloxacin after single intravenous and oral doses. Antimicrob Agents Chemother. 1992; 36(5):993-996.

43. Lubasch A, Keller I, Borner K, Koeppe P, Lode H. Comparative pharmacokinetics of ciprofloxacin, gatifloxacin, grepafloxacin, levofloxacin, trovafloxacin, and moxifloxacin after single oral administration in healthy volunteers. Antimicrob Agents Chemother. 2000; 44(10):2600-2603.

44. Drug@FDA (2020) CIPRO ${ }^{\circledR} \quad$ (ciprofloxacin hydrochloride) TABLETS. Available via https://www.accessdata.fda.gov/drugsatfda docs/lab el/2020/019537s090,020780s047lbl.pdf Accessed $13 / 04 / 2020$.

45. Ngwuluka NC, Nep EI, Ochekpe NA, Odumosu PO, Olorunfemi PO. Eudragit E100 and polysaccharide polymer blends as matrices for modified-release drug delivery II: Swelling and release studies. Tropical Journal of Pharmaceutical Research. 2015; 14(12):2163-2170.

46. Forrest A, Nix DE, Ballow CH, Goss TF, Birmingham MC, Schentag JJ. Pharmacodynamics of intravenous ciprofloxacin in seriously ill patients. Antimicrob Agents Chemother. 1993; 37(5):10731081.

47. Nwaiwu O, Oyelade O, Eze C. Evaluation of Pharmacovigilance Practice in Pharmaceutical Companies in Nigeria. Pharm Med. 2016; 30(5):291295. 